\title{
Optimization of machining parameters in turning of Inconel 718 Nickel-base super alloy
}

\author{
Wassila Frifita ${ }^{1, *}$, Sahbi Ben Salem ${ }^{1,2}$, Abdelkrim Haddad ${ }^{3}$, and Mohamed Athmane Yallese ${ }^{4}$ \\ ${ }^{1}$ Laboratory MAI, National Engineering School of Tunis, University of Tunis El Manar, 1002 Tunis, Tunisia \\ 2 IPEI Nabeul, Mrazka University Campus, 8000 Nabeul, Tunisia \\ ${ }^{3}$ Laboratoire de Mécanique Appliquée des Nouveaux Matériaux (LMANM) Université 8 Mai 1945 Guelma, Guelma, Algeria \\ ${ }^{4}$ Mechanics and Structures Research Laboratory (LMS), May 8th 1945 University, 24000 Guelma, Algeria
}

Received: 14 June 2019 / Accepted: 24 December 2019

\begin{abstract}
The high hardness and low thermal diffusivity along with the tremendous strength at high temperatures has rendered the nickel-base super alloys Inconel 718 one of the most difficult to cut material. It possesses a wide range of applications including aerospace as well as chemical and petrochemical industries, and is primarily used in the manufacture of aircraft gas turbines, space vehicles, nuclear power systems, and medical equipment. The present study is mainly focused on the cutting parameters optimization that leads to minimum surface roughness, cutting force and power, specific energy and maximum productivity during the turning of the molded Inconel 718 using a carbide cutting tool. The analysis of variance (ANOVA) method is applied to identify the cutting parameters that most influence the response criteria, and the response surface methodology (RSM) along with the desirability function (DF) approaches are further used to develop the prediction model that addresses the optimization procedure. The different parameters are considered one at a time in order to evaluate the sensitivity of the response (OFAT). This procedure led to identify the nose radius $\left(r_{\varepsilon}\right)$, the feed rate $(f)$, the depth of cut $\left(a_{\mathrm{p}}\right)$ and the cutting speed $\left(V_{\mathrm{c}}\right)$ as the most significant factors on both the surface roughness and the cutting forces. Furthermore, the product $\left(f \times a_{\mathrm{p}}\right)$ and the cutting speed $\left(V_{\mathrm{c}}\right)$ were found to be the most dominant factors on the specific energy.
\end{abstract}

Keywords: Turning / inconel 718 / ANOVA / surface roughness / response surface methodology / desirability function / cutting forces / optimization

\section{Introduction}

Nickel base alloys such as Inconel 718 (NC19FeNb according to European standards) are the heat resistant super alloys that are widely used in the manufacture of aero-engine, rocket and submarine components that run at temperatures comprised between $450{ }^{\circ} \mathrm{C}$ and $700{ }^{\circ} \mathrm{C}[1,2]$. Unfortunately, the characteristics that lead to it being one of the most important engineering materials are likewise responsible for its poor machinability that usually results in limited tool life and poor surface quality and consequently high costs [3-5]. These are the main reasons that led numerous investigators to carrying out various studies aiming to optimize the machinability of this type of material.

Khidhir et al. [6] investigated the influence of various cutting parameters along with the insert geometry on both the surface rectitude and the tool life in the turning of

\footnotetext{
* e-mail: wassilaenit@gmail.com
}

Hastelloy-276. The nose radius was found to be the most significant factor affecting the surface roughness while the insert geometry was followed by the cutting speed in affecting the tool life.

The parameters influencing the surface roughness have been widely investigated [7-12]. The cutting speed along with the feed rate, the nose radius, the insert type and the material composition have been shown to develop a significant impact on the surface quality.

The work of Grzesik et al. [13] focused mostly on tool wear, and found out that the use of Titanium aluminum nitride coatings (AlTiN and TiAlN) greatly enhances the tool life. The same results were achieved by Akhtar et al. [14] who concluded that all the cutting speed levels applied contributed to the tool wear. Dudzinski [15] confirmed the tool wear as being the major problem in Inconel 718 turning.

Tebassi et al. [16-18] were interested in optimizing the surface roughness quality, the cutting forces, the productivity and the power consumption during the turning of Inconel 718. Applying the RSM approach, they found out 
Table 1. Chemical composition of Inconel 718 alloy.

\begin{tabular}{lllllll}
\hline Element & $\mathrm{Ni}$ & $\mathrm{Cr}$ & $\mathrm{Fe}$ & $\mathrm{C}$ & $\mathrm{Nb}$ & $\mathrm{Mo}$ \\
\hline Wt (\%) & 52.32 & 18.92 & 21 & 0.05 & 4.92 & 3.01 \\
Element & $\mathrm{Si}$ & $\mathrm{Mn}$ & $\mathrm{Co}$ & $\mathrm{Cu}$ & $\mathrm{Ti}$ & $\mathrm{Al}$ \\
Wt $(\%)$ & 0.08 & 0.01 & 0.13 & 0.01 & 0.99 & 0.56 \\
\hline
\end{tabular}

Table 2. Mechanical and physical properties.

\begin{tabular}{|c|c|c|c|c|c|c|c|c|}
\hline \multirow[t]{2}{*}{ Hardness } & \multirow{2}{*}{$\begin{array}{l}\text { Thermal } \\
\text { conductivity }\end{array}$} & \multirow{2}{*}{$\begin{array}{l}\text { Specific } \\
\text { heat }\end{array}$} & \multirow{2}{*}{$\begin{array}{l}\text { Yield strength } \\
R_{\mathrm{p} 0.2}\end{array}$} & \multirow[t]{2}{*}{ Elongation } & \multicolumn{4}{|c|}{ Creep test } \\
\hline & & & & & $\begin{array}{l}\text { Test } \\
\text { temperature }\end{array}$ & Constraint & Time & Elongation \\
\hline $35 \mathrm{HRC}$ & $11.4 \mathrm{~W} / \mathrm{mk}$ & $435 \mathrm{~J} / \mathrm{kg} \mathrm{K}$ & $855 \mathrm{MPa}$ & $7 \%$ & $650^{\circ} \mathrm{C}$ & $620 \mathrm{MPa}$ & $2 \mathrm{~h}$ & $0 \%$ \\
\hline
\end{tabular}

that the feed rate and the cutting speed were the most significant parameters affecting the surface roughness. Furthermore, the depth of cut was identified as the most influential parameter affecting the cutting force, while both the cutting speed and the depth of cut had a great impact on productivity. The Artificial Neural Network (ANN) method was also applied to lead to the same results. Finally, the implementation of the Fraction Design Space (FDS) along with the Box-Cox Plot procedures showed that the surface roughness $\left(R_{\mathrm{a}}\right)$ is mainly affected by both the cutting speed and the nose radius while the depth of cut is the most influential parameter affecting the productivity.

In terms of thermal analysis of Nickel based alloys, Reddy [19] carried out a numerical investigation whose results demonstrated that the cutting temperature increases with the depth of cut and the cutting speed. Parida et al. [20] performed a numerical along with an experimental investigations that led to conclude that the increase in the temperature leads to a similar increase in the friction tool-workpiece along with a reduction of the cutting force.

Numerous researches [21-23] focused on the cutting force parameter and the optimization of the process parameters to reduce it. They concluded that the application of the Minimal Quantity Lubrication (MQL) conditions decreases the cutting force, while the combination MQL-cryogen leads to an increase of it.

Many studies on the machining performance of the laminated Inconel 718 alloy have been performed, including machinability, surface quality, tool wear mechanism and process optimization, but fewer studies that deal with molded Inconel 718 have been reported. The work carried out in this research involves the investigation and optimization of the cutting conditions pertaining to the molded Inconel 718 in order to achieve better surface quality, cutting force and productivity.

\section{Experimental setup and procedure}

\subsection{Work-piece material}

The experiments were performed on a lathe 'TOS TRENCIN, SN40C model' that develops a spindle power of $6.6 \mathrm{~kW}$ and a maximum spindle speed of $2000 \mathrm{rpm}$.

The workpiece material was the Ni-based super alloy Inconel 718 obtained from molding. Its chemical composition is shown in Table 1 while its physical properties are displayed in Table 2 . The experiments are carried out on four samples $30 \mathrm{~mm}$ in length with internal and external diameters equaling 24 and $32 \mathrm{~mm}$ respectively. Each sample is divided into five bearings having a length of $4 \mathrm{~mm}$ each and separated by grooves $2 \mathrm{~mm}$ thick (Fig. 1).

The turning operations were performed under wet conditions. Two inserts having a nose radius of $0.4 \mathrm{~mm}$ (ref. VNMG 120304) and $0.8 \mathrm{~mm}$ (VNMG 120308) were used for cutting. They were secured on a tool holder designed PSBNR25 $\times 25 \mathrm{M} 12$. The inserts were removable, doublesided $35^{\circ}$ rhombic with four cutting edges, and are mainly used for finishing and semi-finishing turning. Their geometry is characterized by $K_{\mathrm{r}}=93, \varepsilon_{\mathrm{r}}=35^{\circ}$ and $\alpha=0^{\circ}$ (Fig. 2).

A two-dimensional roughness meter (Mitutoyo Surftest-201P) was employed for the measurement of the surface roughness. The linear dimension examined had a $2.4 \mathrm{~mm}$ length, and the measurements were performed with a cutoff is $0.8 \mathrm{~mm}$. Due to these small workpiece dimensions, the measurements could not be performed directly on the machine without dismantling the setup. This led to carry out an arithmetic mean roughness for $\left(R_{\mathrm{a}}\right)$ after disassembling the workpiece. However and in order to reduce any uncertainty, four measurements were performed each time. Their average is considered as the roughness value measured. Then, the average roughness values are considered. The cutting forces were measured using a 


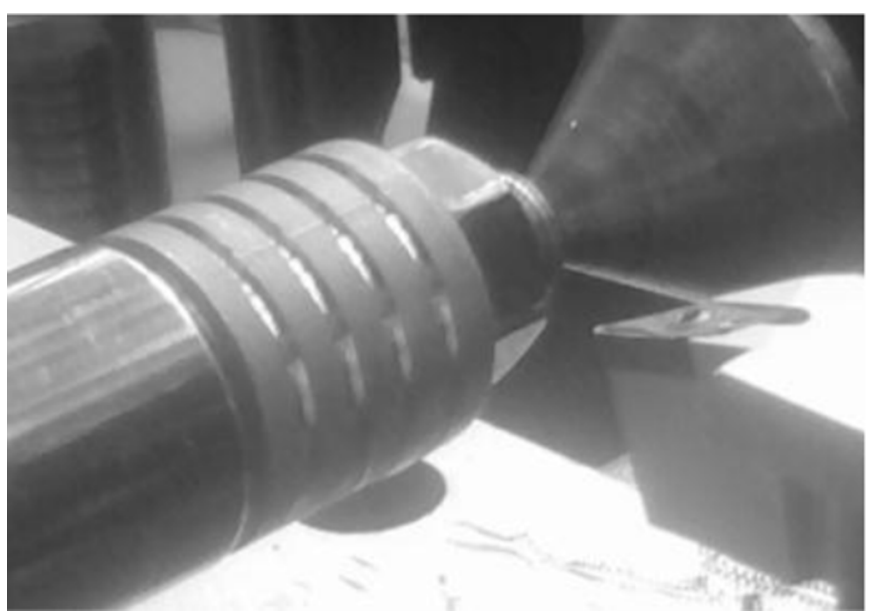

Fig. 1. Workpiece attached to the machining assembly.
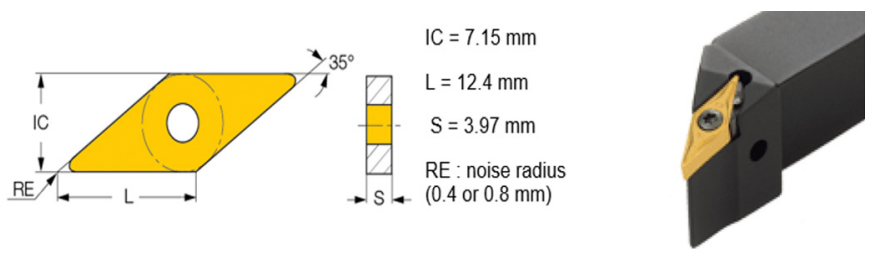

Fig. 2. Cutting tool geometry.

piezoelectric dynamometer (Kistler, model 9257B). The experimental setup along with the schematic diagram of the experimental arrangement is represented in Figure 3.

\subsection{Design of experiments}

Design of experiments is a standard tool used to conduct the experiment in an optimum way to investigate the effects of process parameters illustrated by the cutting conditions and represented by the feed rate $(f)$, the nose radius $\left(r_{\varepsilon}\right)$ and the cutting speed $\left(V_{\mathrm{c}}\right)$ on the response or output parameters i.e. the surface roughness and the three components of the cutting force $\left(F_{\mathrm{a}}, F_{\mathrm{r}}\right.$ and $\left.F_{\mathrm{t}}\right)$ during the machining of the Ni-based super alloy Inconel 718. The nose radius $\left(r_{\varepsilon}\right)$ possesses two levels while the feed rate $(f)$ and the cutting speed $\left(V_{\mathrm{c}}\right)$ possess three (Tab. 3). All levels are selected according to the range provided by the manufacturer. The two different parameter levels necessitate the application of the mixed-levels OA orthogonal array represented by the Taguchi mixed $\mathrm{L}_{18}$ array.

\subsection{Response surface methodology}

The RSM is a combination of statistical and mathematical procedures devoted to the development of mathematical models for analysis and optimization. It is applied to develop a relationship between the response factors and the significant parameters [24]. In this study, the RSM is devoted to the obtaining a regression equation describing the response parameters as a function of the independent process factors. First-order RSM-based mathematical models are herein developed for the arithmetic surface roughness $\left(R_{\mathrm{a}}\right)$ and the three components of the cutting force. In this case the response function may be expressed as:

$$
Y=f(A, B, C, D)
$$

where $(Y)$ is the response and $(A, B, C, D)$ are the process parameters. The multiple linear model is used for the representation of the response variable, and given as:

$$
Y=\alpha_{0}+\sum_{i=1}^{n} \alpha_{i} X_{i}+\sum_{i=1}^{n} \sum_{j=1}^{m} \alpha_{i j} X_{i} X_{j}
$$

where $\alpha_{0}$ : is the free term of the regression equation, $\alpha_{1}, \alpha_{2}$, $\ldots, \alpha_{n}$ : are the linear terms, $\alpha_{i j}$ : are the interaction terms, $X_{i}$ : are the process parameters (inputs).

\section{Results and discussion}

\subsection{The one-factor-at-a-time (OFAT) method}

The one-factor-at-a-time (OFAT) approach consist at performing experiments by varying only one factor or variable at a time while keeping others fixed. This will recognize, in the present case, the influence of each cutting parameter on the mean arithmetic surface roughness $\left(R_{\mathrm{a}}\right)$ and the three cutting force components. To this end, a number of parametric tests have been carried out and the results obtained displayed in Tables 4 and 5 . While Table 4 summarizes the different cutting conditions of the parametric tests displayed in Figures 4 and 5 , Table 5 compiles the impact of the process parameters on both the surface roughness and the cutting forces.

\subsubsection{Effects of cutting parameters on surface roughness}

\subsubsection{Varying the cutting speed}

Figure 4a illustrates the influence of the cutting speed $\left(V_{\mathrm{c}}\right)$ on $\left(R_{\mathrm{a}}\right)$. It may be seen that the surface roughness decreases when the cutting speed increases, and this is the result of the high speed machining which results in less burr formation. Moreover, high-cutting speeds correspond to higher removal rate that accumulates in front of the tool tip affecting the tool profile. As a result, the surface quality will improve. Similar results have been identified by Xavior et al. [25] and Aruna and Dhanalaksmi [26] when turning Inconel 718. Using a CNC lathe under dry machining, Devillez et al. [27] found out that the surface roughness decreases when the cutting speed increases up to $60 \mathrm{~m} / \mathrm{min}$. Beyond $70 \mathrm{~m} / \mathrm{min}$, the surface roughness has a tendency to increase and a result considered the cutting speed of $60 \mathrm{~m} / \mathrm{min}$ as optimal. Kumar et al. [28] obtained the same behavior when turning Inconel 718 under different conditions. They concluded that the best surface roughness is obtained in the velocity range of $65-75 \mathrm{~m} / \mathrm{min}$. 


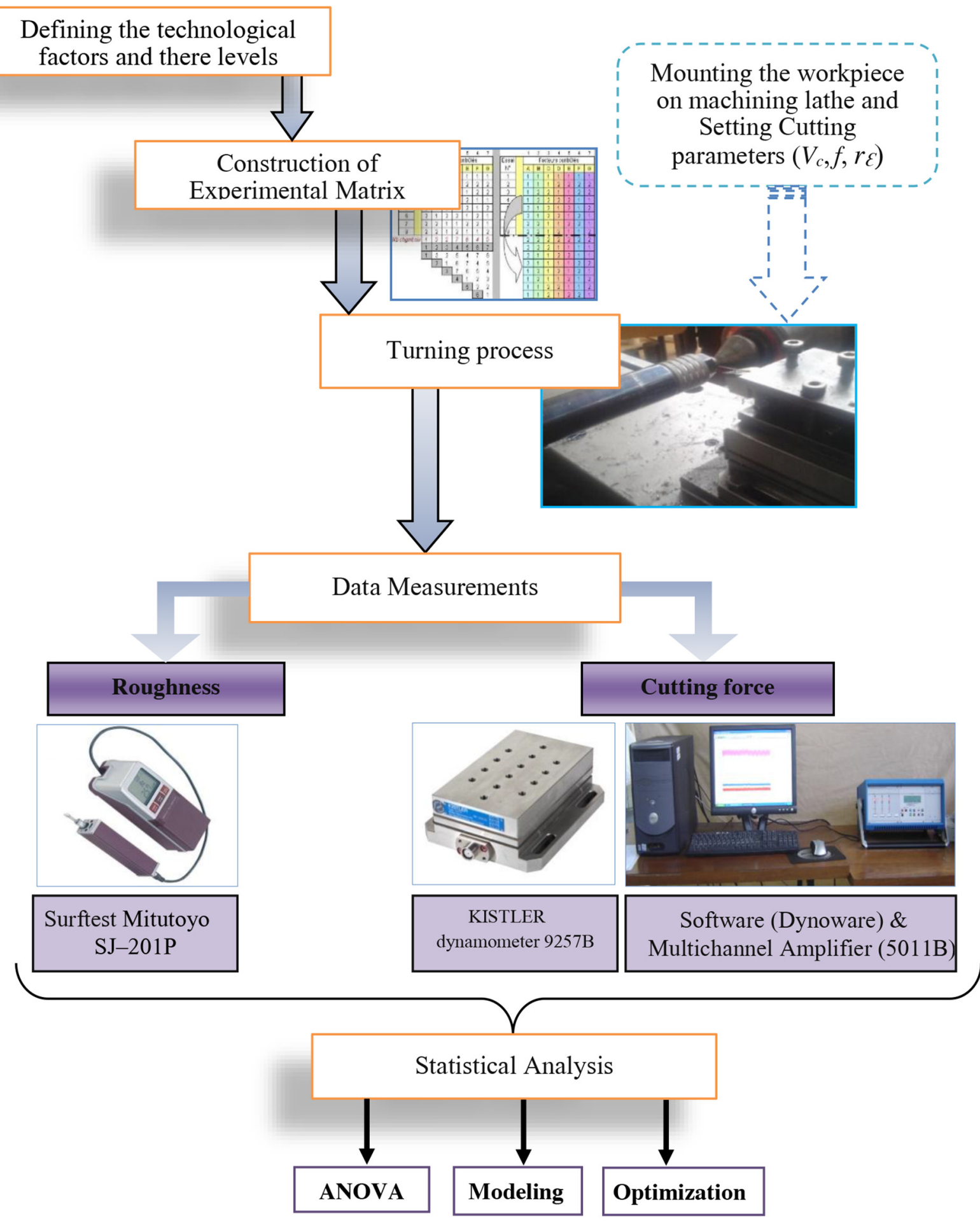

Fig. 3. Experimental set-up.

Table 3. Cutting parameters and their levels.

\begin{tabular}{llll}
\hline Factors & $V_{\mathrm{c}}(\mathrm{m} / \mathrm{min})$ & $f(\mathrm{~mm} / \mathrm{rev})$ & $r_{\varepsilon}(\mathrm{mm})$ \\
\hline Level 1 & 34 & 0.08 & 0.4 \\
Level 2 & 47 & 0.12 & 0.8 \\
Level 3 & 70 & 0.14 & \\
\hline
\end{tabular}

\subsubsection{Varying the feed rate}

One of the most important factors influencing the surface roughness $\left(R_{\mathrm{a}}\right)$ is represented by the feed rate $(f)$ displayed in Figure $4 \mathrm{~b}$. They follow the same trend. Increasing $(f)$ from 0.08 to $0.24 \mathrm{~mm} / \mathrm{rev}$ leads to an increase of $\left(R_{\mathrm{a}}\right)$ from 0.75 to $1.2 \mu \mathrm{m}$. Numerically, a fluctuation of $0.16 \mathrm{~mm} / \mathrm{rev}$ 
Table 4. Cutting parameters of the parametric tests.

\begin{tabular}{lllll}
\hline & Varying & Varying & Varying & Varying $r_{\varepsilon} 0.4$ et 0.8 \\
& $V_{\mathrm{c}}[23.5 ; 94.5]$ & $f[0.08 ; 0.22]$ & $a_{\mathrm{p}}[0.15 ; 0.35]$ & \\
\hline & Figures 4a \& $5 \mathrm{a}$ & Figures $4 \mathrm{~b} \& 5 \mathrm{~b}$ & Figures 4c \& $5 \mathrm{c}$ & Figures 4d \& $5 \mathrm{~d}$ \\
\hline Cutting conditions & $r_{\varepsilon}=0.8 \mathrm{~mm}$ & $r_{\varepsilon}=0.8 \mathrm{~mm}$ & $r_{\varepsilon}=0.8 \mathrm{~mm}$ & Concerns the test number: \\
& $a_{\mathrm{p}}=0.15 \mathrm{~mm}$ & $a_{\mathrm{p}}=0.15 \mathrm{~mm}$ & $f=0.11 \mathrm{~mm} / \mathrm{rev}$ & $1,2,3,4$ for radius 0.4 \\
& $f=0.11 \mathrm{~mm} / \mathrm{rev}$ & $V_{\mathrm{c}}=47 \mathrm{~m} / \mathrm{min}$ & $V_{\mathrm{c}}=47 \mathrm{~m} / \mathrm{min}$ & $10,11,12,13$ for radius 0.4 \\
\hline
\end{tabular}

Table 5. Summary of the impact of the process parameters on the surface roughness and the cutting forces.

\begin{tabular}{lll}
\hline & Impact on surface roughness & Impact on cutting forces \\
\hline $\begin{array}{l}\text { Increasing the cutting speed } \\
\left(V_{\mathrm{c}}\right) \text { from } 30 \text { to } 90 \mathrm{~m} / \mathrm{min}\end{array}$ & $\left(R_{\mathrm{a}}\right)$ decreases by $73.77 \%$ & $\left(F_{\mathrm{a}}\right)$ decreases by $65.8 \%$ \\
& & $\left(F_{\mathrm{r}}\right)$ decreases by $77.2 \%$ \\
Increasing the feed rate $(f)$ & $\left(R_{\mathrm{a}}\right)$ increases by $15.5 \%$ & $\left(F_{\mathrm{t}}\right)$ decreases by $63.1 \%$ \\
from 0.1 to $0.2 \mathrm{~mm} / \mathrm{rev}$ & & $\left(F_{\mathrm{a}}\right)$ increases by $81.9 \%$ \\
& $\left(R_{\mathrm{a}}\right)$ increases by $73.4 \%$ \\
$\begin{array}{l}\text { Increasing the depth of cut } \\
\left(a_{\mathrm{p}}\right) \text { from } 0.2 \text { to } 0.3 \mathrm{~mm}\end{array}$ & & $\left(F_{\mathrm{t}}\right)$ increases by $68.7 \%$ \\
$\begin{array}{l}\text { Increasing the insert radius } \\
\left(r_{\varepsilon}\right) \text { from } 0.4 \text { to } 0.8 \mathrm{~mm}\end{array}$ & $\left(F_{\mathrm{a}}\right)$ increases by $74.2 \%$ \\
$V_{\mathrm{c}}=34 \mathrm{~m} / \mathrm{mn}$ & $\left(F_{\mathrm{r}}\right)$ increases by $24.3 \%$ \\
$f=0.08 \mathrm{~mm} / \mathrm{rev}$ & From 1.02 to 0.82 & $\left(F_{\mathrm{t}}\right)$ increases by $21.7 \%$ \\
$a_{\mathrm{p}}=0.15 \mathrm{~mm}$ & & from 11.43 to $13.74 \mathrm{~N}$ \\
\hline
\end{tabular}
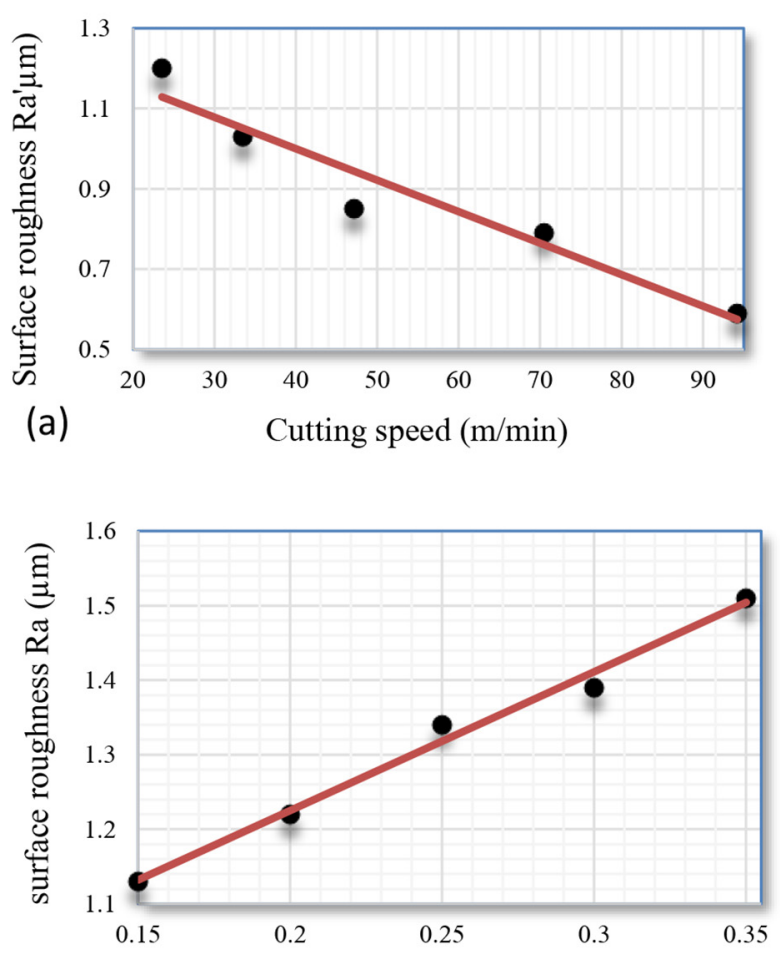

(c)
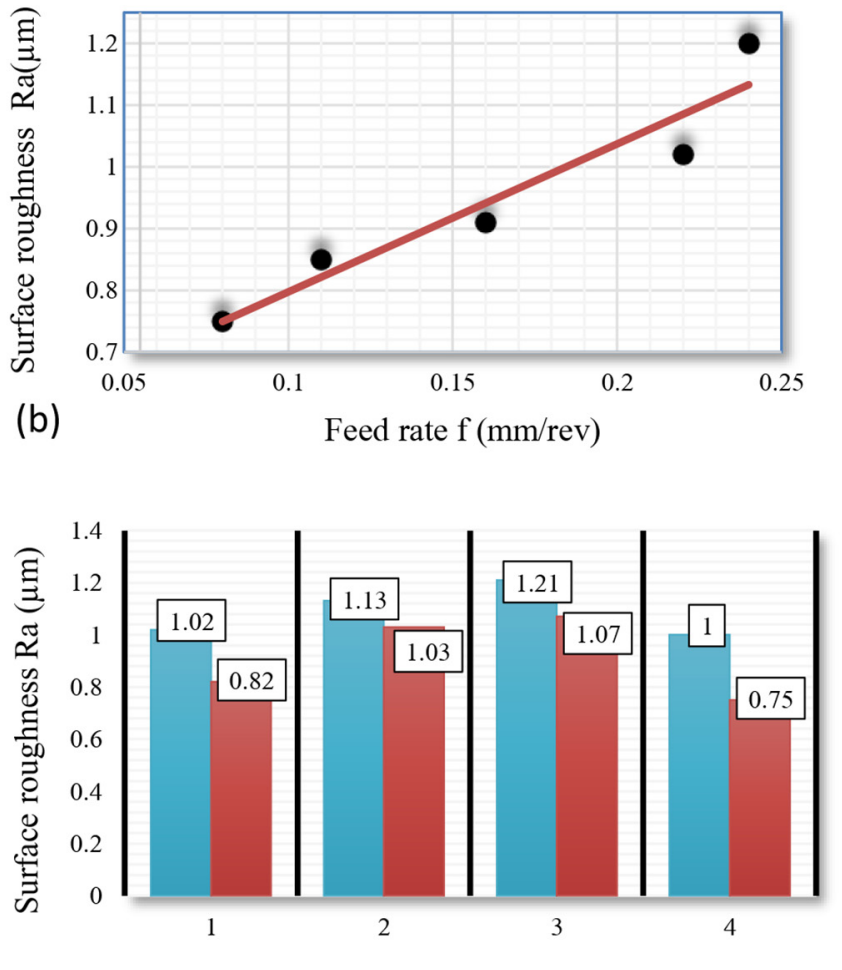

(d) $\quad$ radius $=0.4 \quad$ radius $=0.8$

Fig. 4. Influence of the cutting parameters on the surface roughness $\left(R_{\mathrm{a}}\right)$. 

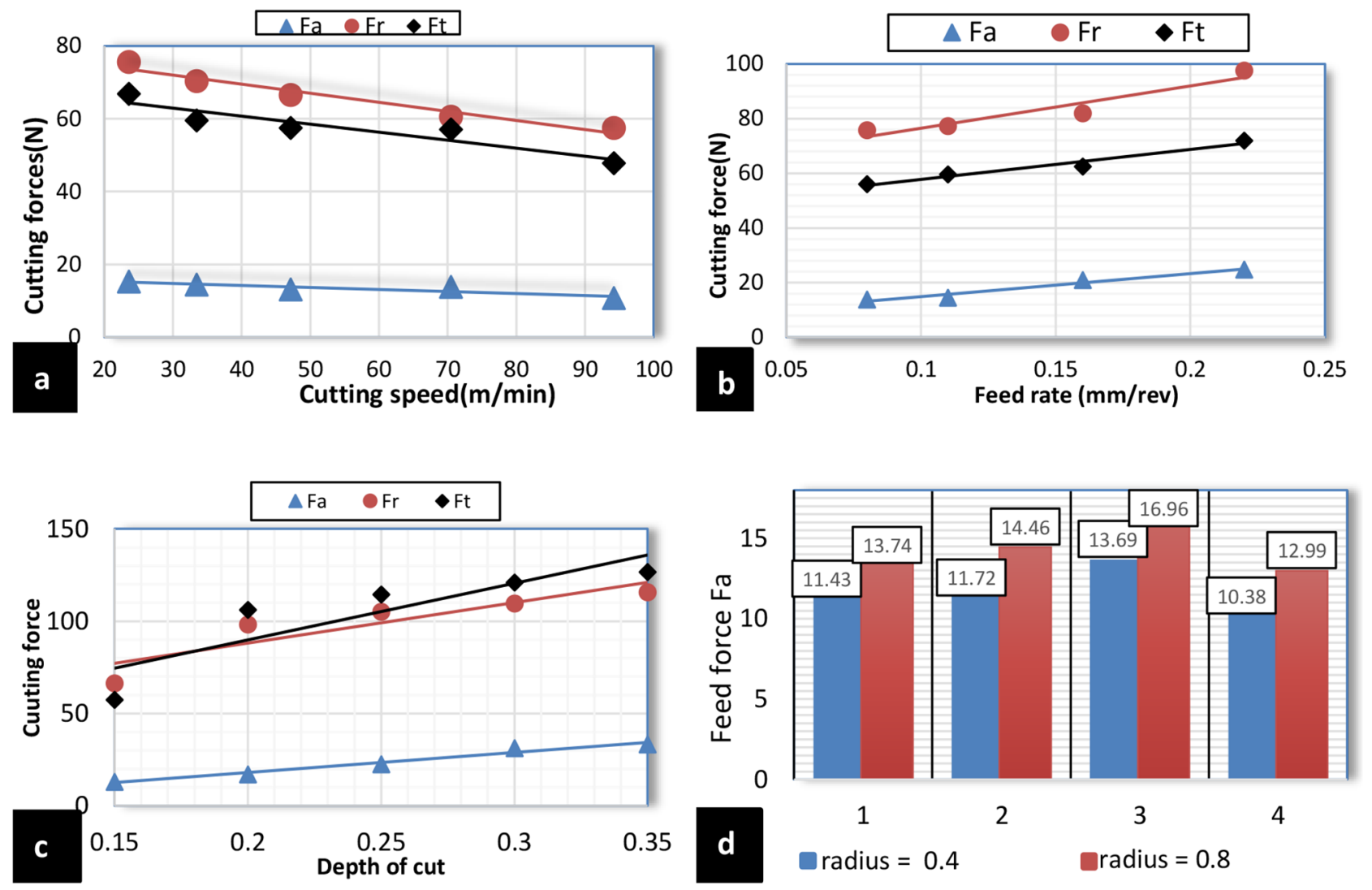

Fig. 5. Influence of the cutting parameters on the cutting forces.

in the feed rate alters $\left(R_{\mathrm{a}}\right)$ by $0.45 \mu \mathrm{m}$ and it is mainly for this reason that surface roughness is generally considered a function of the square of the feed rate. Such results involving the effects of both the feed rate $(f)$ and the cutting speed $\left(V_{\mathrm{c}}\right)$ on the surface roughness criterion $\left(R_{\mathrm{a}}\right)$ have been reported by Thakur et al. [29] during turning of Inconel 718 with depth of cut of $a_{\mathrm{p}}=0.5 \mathrm{~mm}$. Similarly, Darwish [9] worked on the surface roughness of Inconel 718 using CBN and ceramic inserts under dry conditions. His results led to considering the surface quality as mainly sensitive to the feed rate and that any increase of the latter increases accordingly the surface roughness.

\subsubsection{Varying the depth of cut}

With the exception of the first experiment result in Figure 4b, the curve shape representing the fluctuation of $\left(R_{\mathrm{a}}\right)$ as a function of $(f)$ tends to follow a quadratic function. However and in practice, this tendency is not verified. Indeed and when the feed rate moves towards zero, MRR decreases significantly as it is controlled by the material tearing phenomena which alters the surface quality.

Figure 4c displays the variation of the surface roughness $\left(R_{\mathrm{a}}\right)$ in terms of the depth of cut $\left(a_{\mathrm{p}}\right)$. Curve seems to follow linear behavior. This is a characteristic of metal machining in which any increase in feed rate or depth of cut leads to an increase in the cross-section and the deformed volume, and consequently results in higher surface roughness values. Darwish [9] noticed the same behavior of $\left(R_{\mathrm{a}}\right)$ in terms of the depth of cut. Moreover, the material behavior is found to be naturally sticky which makes chips detachment difficult and may lead to a degradation of the surface roughness. The investigation carried out by Xuan-Truong et al. [30] showed the depth of cut having no influence on the surface roughness during the turning of on Inconel 718. This can be explained by the use of a PVD-coated tool that is able to reduce the depth of cut effects.

\subsubsection{Varying the nose radius}

Figure $4 \mathrm{~d}$ refers to the first four experiments of each nose radius (i.e. tests $1-2-3-4$ for the nose radius of $0.4 \mathrm{~mm}$ and 10-11-12-13 for the nose radius of $0.8 \mathrm{~mm}$ ) illustrated in the $\mathrm{L}_{18}$ table (Tab. 6). Figure $4 \mathrm{~d}$ displays the influence of the nose radius on $\left(R_{\mathrm{a}}\right)$. It is found that the best roughness is obtained when using the large nose radius (i.e. $0.8 \mathrm{~mm}$ ) that corresponds to test 4 in Figure 4 d. In fact, the cutting insert shape is first reproduced on the work-piece surface then the large nose radius increases the tool tip contact that minimizes the appearance of surface irregularities along the surface. It leads to crushing any asperity [20]. Conversely and in the case of the low nose radius (i.e. $0.4 \mathrm{~mm}$ ), the number of irregularities related to the tool shape is found to be more important along the same measurement length. 


\subsubsection{Effects of cutting parameters on cutting forces 3.1.2.1 Varying the cutting speed}

Figure 5 a shows the variations of the feed force, the thrust force and the tangential force with the cutting speed $\left(V_{\mathrm{c}}\right)$. It may be seen that an increase in the cutting speed leads to a decrease of the three cutting force components. This is due to the fact that an increase of the cutting speed drives an equal augmentation of the temperature that leads to a decrease of the mechanical workpiece properties in the cutting area and consequently that of the surface hardness and the cutting forces. These results have been encountered by Thakur et al. [29] who performed a machining the Inconel 718 with Tungsten carbide cutting tool inserts (K20) under high speed turning. Parida et al. [20] applied a finite element analysis in hot conditions machining. They stimulated the decrease of the cutting force with an increase of the cutting speed due to a temperature rise in the cutting zone and a reduction of the friction coefficient. The irregular curve shapes of Figure 5a and c may be explained by the turning process conditions along with possible vibrations that take place during a conventional turning process.

\subsubsection{Varying the feed rate, the depth of cut and the nose radius}

The cutting forces increase proportionally with the other process parameters (i.e. feed rate, depth of cut and nose radius) and this is illustrated in Figure $5 \mathrm{~b}-\mathrm{d}$, this latter referring to the first four experiments of each nose radius (i.e. tests 1-2-3-4 for the nose radius of $0.4 \mathrm{~mm}$ and $10-11-$ $12-13$ for the nose radius of $0.8 \mathrm{~mm}$ ) illustrated in the $\mathrm{L}_{18}$ table. The results obtained show high values of $(f),\left(a_{\mathrm{p}}\right)$ and $\left(r_{\varepsilon}\right)$ corresponding to high material shape removal rate and equal important grooves generated by the helical movement that in turn requires higher cutting forces. This seems to agree with the results obtained by Thakur et al. [29] concerning the feed rate. Furthermore, under a high feed rate and a low cutting speed, the coefficient of friction toolworkpiece is found to be larger leading to greater cutting forces. However, at greater cutting speeds and feed rates, the cutting forces tend to decrease due to higher temperature generated and consequently a softer material. Concerning the nose radius, Parida et al. [20] concluded that the larger the nose radius is, the more important the tool bluntness and tool tip contact are and that lead to greater force values. Based on its specific thermal conductibility, the heat generated during the Inconel 718 machining is carried away by the chips. This is an advantage that protects the work-piece.

Table 5 summarizes the results of the different results obtained concerning the influence of the process parameters on both the surface roughness and the cutting forces. It is clear that all the cutting parameters do have an influence on the response factors, and that each parameter is characterized by its degree of significance that will be demonstrated by the application of ANOVA analysis.

According to above-mentioned results pertaining to the parametric tests, it is possible to conclude that machining Inconel 718 under high cutting speed values, high feed rate and low nose radius presents the optimum combination case that leads to simultaneously improve the surface quality along with cutting forces.

\subsubsection{Effect on the cutting power $\left(P_{\mathrm{c}}\right)$ and the material removal rate (MRR)}

Figure 7 shows the impact of the cutting speed, the feed rate and the depth of cut on both the cutting power $\left(P_{\mathrm{c}}\right)$ and the material removal rate (MRR). The two responses may be expressed in terms of $\left(V_{\mathrm{c}}\right)(f)$ and $\left(a_{\mathrm{p}}\right)$ as:

$$
\begin{gathered}
P_{\mathrm{c}}=\frac{F_{\mathrm{t}} \times V_{\mathrm{c}}}{60} \\
\mathrm{MRR}=V_{\mathrm{c}} \times f \times a_{\mathrm{p}} .
\end{gathered}
$$

The response parameters $\left(P_{\mathrm{c}}\right)$ and $(\mathrm{MRR})$ are linearly dependent on the cutting parameters as illustrated in the corresponding curves. Increasing the cutting speed improves the shape of the chips removed per time unit. Similarly, any increase in the feed rate or the depth of cut leads to a similar increase in the chip section. Consequently, (MRR) increases in both situations.

Another important machining aspect is represented by the specific energy or specific pressure noted $\left(K_{\mathrm{c}}\right)$ that may be written as:

$$
K_{\mathrm{c}}=\frac{F_{\mathrm{t}}}{a_{\mathrm{p}} \times f} .
$$

The specific energy is a characteristic of the material machinability. It depends on the used material and the cutting conditions, particularly the cutting speed. An increase of the speed leads to a decrease of the force and consequently that of the pressure. Furthermore, the inverse of the product $\left(a_{\mathrm{p}} \times f\right)$ representing the chip section is an important factor upon which the specific energy heavily depends (Fig. 6).

\subsection{Modeling results}

\subsubsection{Orthogonal array}

The mixed-level rectangular array $\mathrm{L}_{18}$ is applied to investigate the effects of the three factors (i.e. $V_{\mathrm{c}}, f$ and $r_{\varepsilon}$ ) on the arithmetic mean surface roughness $\left(R_{\mathrm{a}}\right)$ and the three components of the cutting force. The experimental results are displayed in Table 6 and will be applied for the analysis of the input parameters impact along with their interaction on each response factor.

\subsubsection{ANOVA analysis}

ANOVA is a computational technique that enables the estimation of the relative contributions of each of the control factors to the overall measured response. Its purpose is to determine the parameters that significantly affect the response variable [31]. The ANOVA tables represented by Tables $7-10$ integrate the sums of squares 

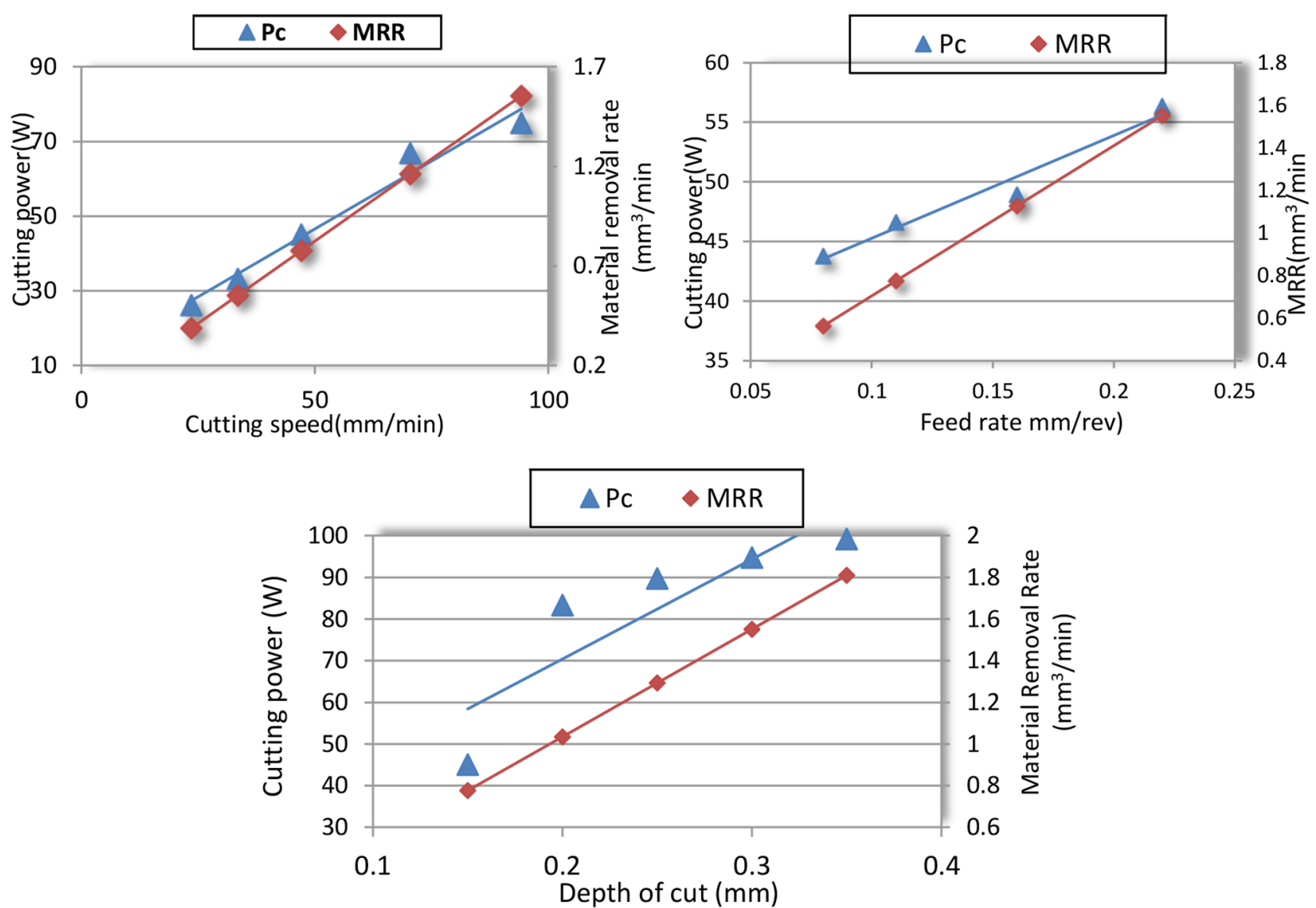

Fig. 6. Influence of the cutting speed, the feed rate and the depth of cut on $\left(P_{\mathrm{c}}\right)$ and $(\mathrm{MRR})$.
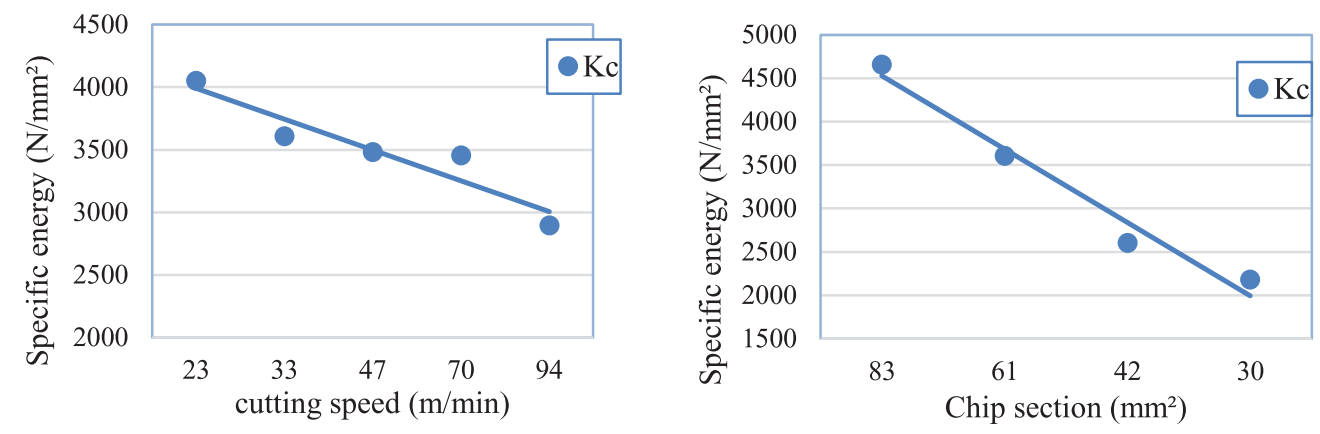

Fig. 7. Specific energy vs. cutting speed and chip section.

(SS), the degrees of freedom (DF), the mean square (MS) representing the ratio of the sum of squares to the degrees of freedom, $F$-values describing The ratio of contribution of the different factors (Contr. \%) and the $P$-values (Prob.) that evaluates the statistical significance of the fitted multiple linear models. $P$-values indicate the significance of the tested parameter (considered when $P$-value $>0.05$ ). In this study, the parameters that display $P$-value below 0.05 will be considered insignificant.
The correlation coefficient $\left(R^{2}\right)$ representing the correlation accuracy indicates the degree of accuracy between the functional relationships combining the dependent variables to the investigated dependent variables. Adjusted $R^{2}$-values are particularly useful when comparing models that show different number of terms.

Tables $7-10$ present the results pertaining to the application of ANOVA for $\left(R_{\mathrm{a}}\right)$ and the cutting forces represented by $\left(F_{\mathrm{a}}, F_{\mathrm{r}}\right.$ and $\left.F_{\mathrm{t}}\right)$. 
Table 6. $\mathrm{L}_{18}\left(2^{1} \times 3^{2}\right)$ OA, experimental results for surface roughness and cutting forces.

\begin{tabular}{|c|c|c|c|c|c|c|c|}
\hline \multirow[t]{2}{*}{ Test No } & \multicolumn{3}{|c|}{ Machining parameters } & \multicolumn{3}{|c|}{ Cutting forces } & \multirow{2}{*}{$\begin{array}{l}\text { Surface roughness } \\
R_{a}(\mu \mathrm{m}) \\
\end{array}$} \\
\hline & $r_{s}(\mathrm{~mm})$ & $V_{c}(\mathrm{~m} / \mathrm{min})$ & $f(\mathrm{~mm} / \mathrm{rev})$ & $F_{a}(\mathrm{~N})$ & $F_{r}(\mathrm{~N})$ & $F_{t}(\mathrm{~N})$ & \\
\hline 1 & 0.4 & 34 & 0.08 & 11.43 & 45.07 & 36.96 & 1.02 \\
\hline 2 & 0.4 & 34 & 0.11 & 11.72 & 48.28 & 48.39 & 1.13 \\
\hline 3 & 0.4 & 34 & 0.14 & 13.69 & 51.41 & 56.45 & 1.21 \\
\hline 4 & 0.4 & 47 & 0.08 & 10.38 & 35.08 & 35.72 & 1 \\
\hline 5 & 0.4 & 47 & 0.11 & 11.5 & 48.32 & 40.8 & 0.97 \\
\hline 6 & 0.4 & 47 & 0.14 & 11.76 & 50.46 & 47.82 & 1.1 \\
\hline 7 & 0.4 & 70 & 0.08 & 10.42 & 34.77 & 32.52 & 0.89 \\
\hline 8 & 0.4 & 70 & 0.11 & 9.72 & 35.82 & 33.85 & 0.92 \\
\hline 9 & 0.4 & 70 & 0.14 & 9.97 & 45 & 43.43 & 1.01 \\
\hline 10 & 0.8 & 34 & 0.08 & 13.74 & 75.69 & 55.92 & 0.82 \\
\hline 11 & 0.8 & 34 & 0.11 & 14.46 & 77.3 & 59.52 & 1.03 \\
\hline 12 & 0.8 & 34 & 0.14 & 16.96 & 77.43 & 71.05 & 1.07 \\
\hline 13 & 0.8 & 47 & 0.08 & 12.99 & 72.41 & 54.98 & 0.75 \\
\hline 14 & 0.8 & 47 & 0.11 & 13.07 & 84 & 57.48 & 0.85 \\
\hline 15 & 0.8 & 47 & 0.14 & 15.74 & 85.52 & 62.74 & 0.99 \\
\hline 16 & 0.8 & 70 & 0.08 & 12.37 & 73.03 & 53.67 & 0.68 \\
\hline 17 & 0.8 & 70 & 0.11 & 13.75 & 83.5 & 57 & 0.79 \\
\hline 18 & 0.8 & 70 & 0.14 & 14.17 & 94.6 & 61.06 & 0.89 \\
\hline
\end{tabular}

Table 7. ANOVA analysis for $\left(F_{\mathrm{a}}\right)$.

\begin{tabular}{lllllll}
\hline Source & SS & DF & MS & $F$-value & Prob. & Remarks \\
\hline Model & 64.51 & 6 & 10.75 & 34.72 & $<0.0001$ & Significant \\
A-r & 39.82 & 1 & 39.82 & 128.58 & $<0.0001$ & Significant \\
B-Vc & 10.71 & 1 & 10.71 & 34.60 & 0.0001 & Significant \\
C-f & 8.94 & 1 & 8.94 & 28.87 & 0.0002 & Significant \\
AB & 0.34 & 1 & 0.34 & 1.11 & 0.3156 & Insignificant \\
AC & 1.75 & 1 & 1.75 & 5.64 & 0.0368 & Significant \\
BC & 2.21 & 1 & 2.21 & 7.14 & 0.0217 & Significant \\
Residual & 3.41 & 11 & 0.31 & & $R^{2}$ & 0.95 \\
Error total & 67.92 & 17 & & & Adjusted $R^{2}$ & 0.92 \\
Press & 8.77 & & & & Predicted $R^{2}$ & 0.87 \\
\hline
\end{tabular}

Table 7 displays the analysis of variance results concerning the feed force $\left(F_{\mathrm{a}}\right)$. They clearly show the great influence of the nose radius on the feed force with a contribution of $58.63 \%$. It is followed by the cutting speed and feed rate with $15.77,13.16 \%$ contributions respectively. The remaining terms of interactions display such small contributions that they may be considered insignificant.

The ANOVA results concerning the thrust force $\left(F_{\mathrm{r}}\right)$ are displayed in Table 8 . Once again, the nose radius shows the highest influence with a contribution of $91.06 \%$ followed by the feed rate $(6.15 \%)$ and the interaction $\left(r_{\varepsilon} \times V_{\mathrm{c}}\right)$ with a contribution of $3.03 \%$. The cutting speed and the remaining two interaction terms display negligible contributions.

Similarly to the feed and the tangential forces cases, both the nose radius and the feed rate show the greatest contributions ( 66.48 and $19.61 \%$ respectively) in the case of tangential force $\left(F_{\mathrm{t}}\right)$ exhibited in Table 9 . They are followed by the cutting speed with a contribution of $8.11 \%$. 
Table 8. ANOVA analysis for $\left(F_{\mathrm{r}}\right)$.

\begin{tabular}{lllllll}
\hline Source & SS & DF & MS & $F$-value & Prob. & Remarks \\
\hline Model & 6688.23 & 6 & 1114.70 & 110.16 & $<0.0001$ & Significant \\
A-r & 6191.89 & 1 & 6191.89 & 611.91 & $<0.0001$ & Significant \\
B-Vc & 7.05 & 1 & 7.05 & 0.70 & 0.4216 & Insignificant \\
C-f & 417.93 & 1 & 417.93 & 41.30 & $<0.0001$ & Significant \\
AB & 206.32 & 1 & 206.32 & 20.39 & 0.0009 & Significant \\
AC & 1.67 & 1 & 1.67 & 0.16 & 0.6928 & Insignificant \\
BC & 60.40 & 1 & 60.40 & 5.97 & 0.0326 & Significant \\
Residual & 111.31 & 11 & 10.12 & & $R^{2}$ & 0.98 \\
Error total & 6799.54 & 17 & & & Adjusted $R^{2}$ & 0.97 \\
Press & 378.72 & & & & Predicted $R^{2}$ & 0.94 \\
\hline
\end{tabular}

Table 9. ANOVA analysis for $\left(F_{\mathrm{t}}\right)$.

\begin{tabular}{lllllll}
\hline Source & SS & DF & MS & $F$-value & Prob. & Remarks \\
\hline Model & 2018.67 & 6 & 336.44 & 41.04 & $<0.0001$ & Significant \\
A-r & 2056.27 & 6 & 342.71 & 71.71 & $<0.0001$ & Significant \\
B-Vc & 1401.95 & 1 & 1401.95 & 293.34 & $<0.0001$ & Significant \\
C-f & 171.09 & 1 & 171.09 & 35.80 & $<0.0001$ & Significant \\
AB & 413.60 & 1 & 413.60 & 86.54 & $<0.0001$ & Significant \\
AC & 25.43 & 1 & 25.43 & 5.32 & 0.0415 & Significant \\
BC & 12.44 & 1 & 12.44 & 2.60 & 0.1349 & Insignificant \\
Residual & 52.57 & 11 & 4.78 & & $R^{2}$ & 0.97 \\
Error total & 2108.85 & 17 & & & Adjusted $R^{2}$ & 0.96 \\
Press & 165.88 & & & & & 0.92 \\
\hline
\end{tabular}

Table 10. ANOVA analysis for $\left(R_{\mathrm{a}}\right)$.

\begin{tabular}{lllllll}
\hline Source & SS & DF & MS & $F$-value & Prob. & Remarks \\
\hline Model & 0.31 & 6 & 0.052 & 34.61 & $<0.0001$ & Significant \\
A-r & 0.10 & 1 & 0.10 & 69.57 & $<0.0001$ & Significant \\
B-Vc & 0.096 & 1 & 0.096 & 63.93 & $<0.0001$ & Significant \\
C-f & 0.099 & 1 & 0.099 & 65.76 & $<0.0001$ & Significant \\
$\mathrm{AB}$ & $1.778 \times 10^{-5}$ & 1 & $1.78 \times 10^{-5}$ & 0.012 & 0.9155 & Insignificant \\
$\mathrm{AC}$ & $7.008 \times 10^{-3}$ & 1 & $7.01 \times 10^{-3}$ & 4.65 & 0.0541 & Insignificant \\
$\mathrm{BC}$ & $1.275 \times 10^{-3}$ & 1 & $1.27 \times 10^{-3}$ & 0.85 & 0.3775 & Insignificant \\
Residual & 0.017 & 11 & $1.51 \times 10^{-3}$ & & $R^{2}$ & 0.95 \\
Error total & 0.33 & 17 & & & Adjusted $R^{2}$ & 0.92 \\
Press & 0.032 & & & & Predicted $R^{2}$ & 0.90 \\
\hline
\end{tabular}

Finally and concerning the roughness $\left(R_{\mathrm{a}}\right)$ whose results are presented in Table 10, again the nose radius, the feed rate and the cutting speed show the greatest effects with contributions of $31.81,30.07$ and $29.23 \%$ respectively. The contributions of the three interactions terms are found to be less than $5 \%$. In his study, Darwish [9] considered the impact of both the cutting speed and the feed rate on the surface roughness integrity. He found the feed rate as the dominant factor followed by the depth of cut. 


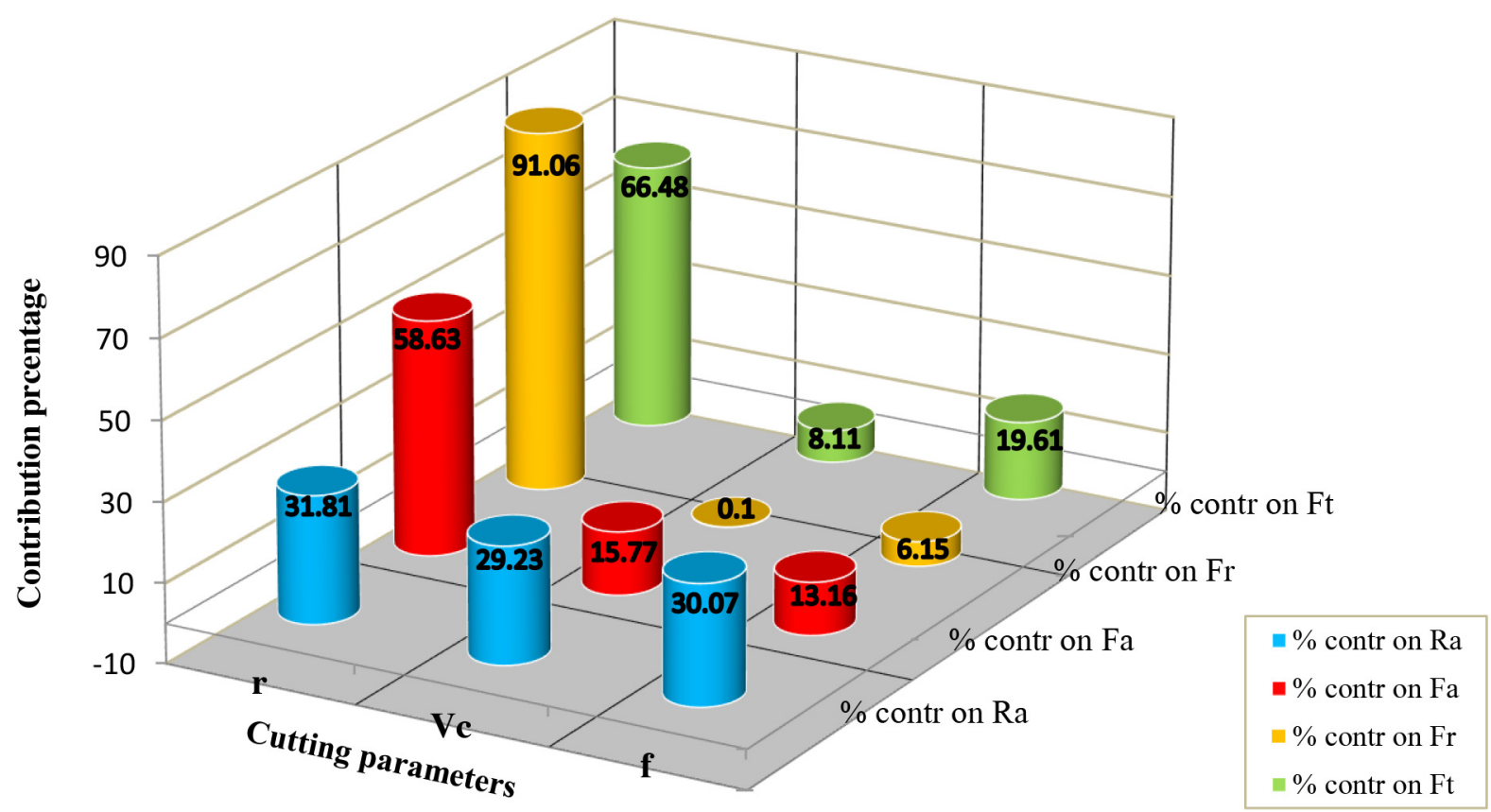

Fig. 8. Contribution of the cutting parameters on the response factors.

The ANOVA results pertaining to all the contributions of the process parameters to each response factor have been gathered and plotted in Figure 8.

\subsubsection{Regression equations for the various responses}

The functional relationships pertaining to the response parameters and combining the dependent variables have been developed. The models integrating the cutting parameters along with their determination coefficients are expressed by equations (6)-(9).

\section{See equations (6)-(9) below.}

The above regression equations are used to compute the prediction values of the response factors at different particular points of the considered study gap. The comparison between the actual (measured) and predicted responses are illustrated in Figure 9. It clearly shows the adequacy of the linear models with interactions which closely simulate the studied factors.

The visualization of both the main and interactions effects on the response factors are presented in Figure 10. It provides the possibility of not only investigating the influence of each factor apart but also their important interactions, the most significant parameter corresponding to the curve with the highest slope. Figures $10 \mathrm{a}-\mathrm{d}$ clearly show the nose radius as the parameter displaying the most decisive impact on the various responses. The same trend may be noticed for the feed rate which, except for the thrust force, shows great influence. The lowest impact is displayed by the depth of cut.

The interaction contours displayed in Figures 10b and d show parallel and crossing curves. Parallel lines indicate no

$$
\begin{aligned}
& \left\{\begin{array}{l}
F_{\mathrm{a}}=7.78-1.86 \times r_{\varepsilon}+0.025 \times V_{\mathrm{c}}+39.46 \times f+0.045 \times r_{\varepsilon} \times V_{\mathrm{c}}+63.61 \times r_{\varepsilon} \times f-0.94 \times V_{\mathrm{c}} \times f \\
R^{2}=0.95
\end{array}\right. \\
& \left\{\begin{array}{l}
F_{\mathrm{r}}=53.08+28.83 \times r_{\varepsilon}-1.24 \times V_{\mathrm{c}}-93.84 \times f+1.11 \times r_{\varepsilon} \times V_{\mathrm{c}}+62.08 \times r_{\varepsilon} \times f+4.9 \times V_{\mathrm{c}} \times f \\
R^{2}=0.98
\end{array}\right. \\
& \left\{\begin{array}{l}
F_{\mathrm{t}}=-5.75+42.82 \times r_{\varepsilon}-0.068 \times V_{\mathrm{c}}+472.22 \times f+0.39 \times r_{\varepsilon} \times V_{\mathrm{c}}-169.72 \times r_{\varepsilon} \times f-3.34 \times V_{\mathrm{c}} \times f \\
R^{2}=0.97
\end{array}\right. \\
& \left\{\begin{array}{l}
R_{\mathrm{a}}=1.21-0.81 \times r_{\varepsilon}-2.12 \times 10^{-3} \times V_{\mathrm{c}}+1.8 \times f-3.25 \times 10^{-4} \times r_{\varepsilon} \times V_{\mathrm{c}}+4.03 \times \mathrm{r}_{\varepsilon} \times f-0.022 \times V_{\mathrm{c}} \times f \\
R^{2}=0.95
\end{array}\right.
\end{aligned}
$$



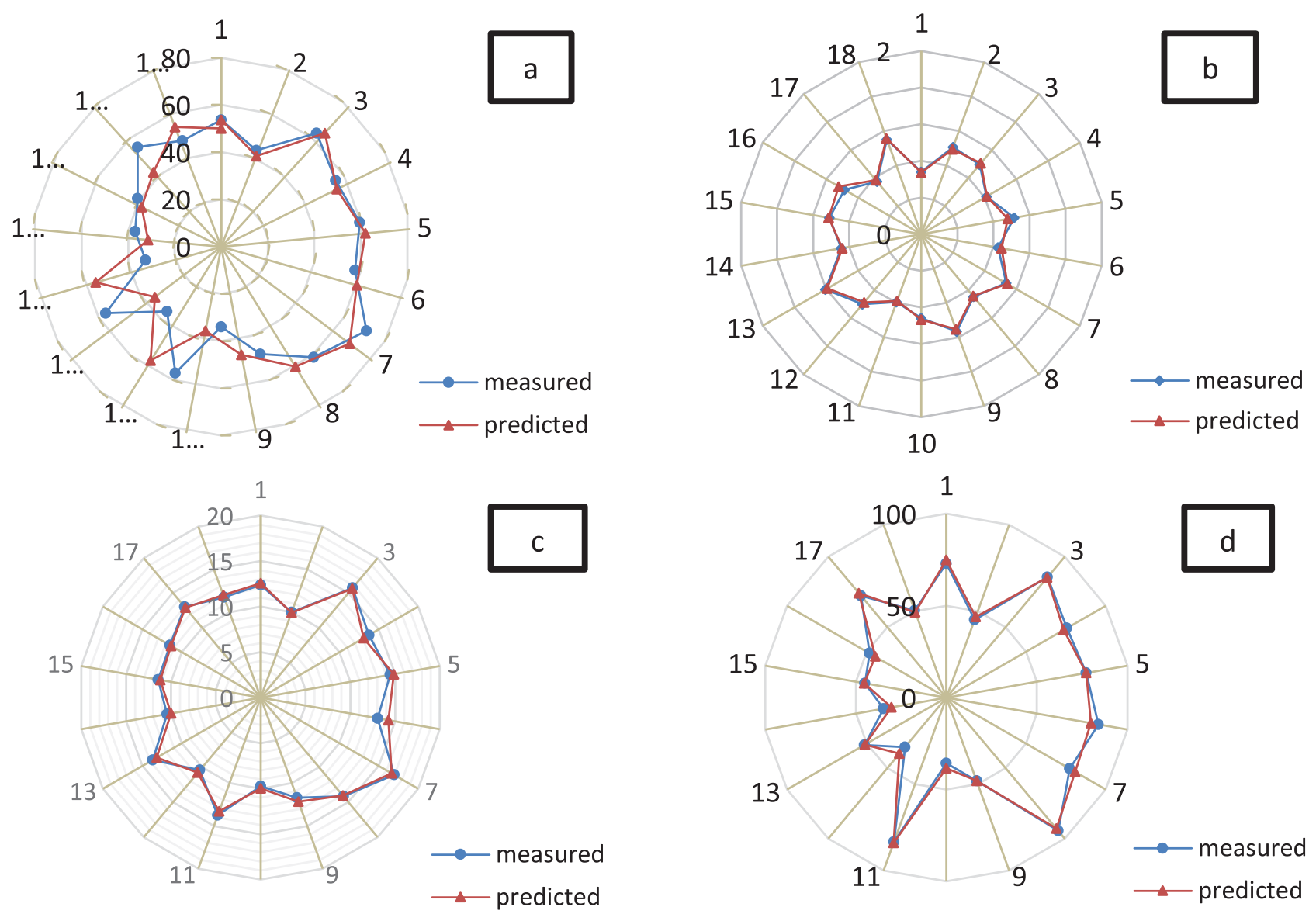

Fig. 9. Measured vs. predicted values of the technological parameters: (a) feed force, (b) thrust force, (c) tangential force and (d) surface roughness.

interaction while the crossing ones demonstrate the strength of the interaction. In Figure 10d, it is clear that the relation between the tangential force and the cutting speed is mainly dependent on the feed rate. If a cutting speed of $47 \mathrm{~m} / \mathrm{min}$ is selected, the minimum feed force will then be obtained for a feed rate of $0.11 \mathrm{~mm} / \mathrm{rev}$. However, if a cutting speed of $34 \mathrm{~m} / \mathrm{min}$ is selected, the minimum feed force will correspond to a feed rate of $0.08 \mathrm{~mm} / \mathrm{rev}$.

\subsubsection{Confirmation tests}

In order to validate the mathematical models developed for $\left(R_{\mathrm{a}}\right)$ and the three components of the cutting force $\left(F_{\mathrm{a}}, F_{\mathrm{r}}\right.$ and $\left.F_{\mathrm{t}}\right)$ and expressed by equations $(6)-(9)$, four confirmation tests were carried out. Their results are displayed in Table 11 and their graphical representation in Figure 11. The difference noticed between the predicted and the experimental results corresponds to the percentage of the Mean Absolute Error (\%MAE) expressed as:

$$
\% \mathrm{MAE}=\left(\frac{1}{n} \sum_{i=1}^{n}\left|\frac{e_{i}-p_{i}}{e_{i}}\right|\right) \times 100
$$

where: $\left(e_{i}\right)$ and $\left(p_{i}\right)$ represent the experimental and predicted parameters, and $(n)$ the number of confirmation tests.

\subsubsection{Interactions effects on responses}

Based on the regression equations (6)-(9), the interaction effects influence on the response parameters $\left(R_{\mathrm{a}}, F_{\mathrm{a}}, F_{\mathrm{r}}\right.$, and $F_{\mathrm{t}}$ ) are represented in Figures 12-15 respectively. They describe the impact of the diverse two-factor interaction (the third being kept constant) on responses during the turning of Inconel 718 using a carbide tool and applying a depth of cut $a_{\mathrm{p}}=0.15 \mathrm{~mm}$.

Figures $12 \mathrm{a}$ and $\mathrm{c}$ show the inverse influence relationship of the cutting speed on surface roughness. Indeed, the increase of the cutting speed generates a decrease of the surface roughness. Therefore, the best surface roughness may be obtained with the highest cutting speed. Figure $12 \mathrm{~b}$ displays the impact of the interaction insert radius-feed rate $\left(r_{\varepsilon}-f\right)$. At constant feed rate, the surface roughness decreases with the increase of the insert radius. However, $\left(R_{\mathrm{a}}\right)$ increases with the feed rate and inversely. This is the result of the generation of deeper furrows in the case of increase of the feed rate. 

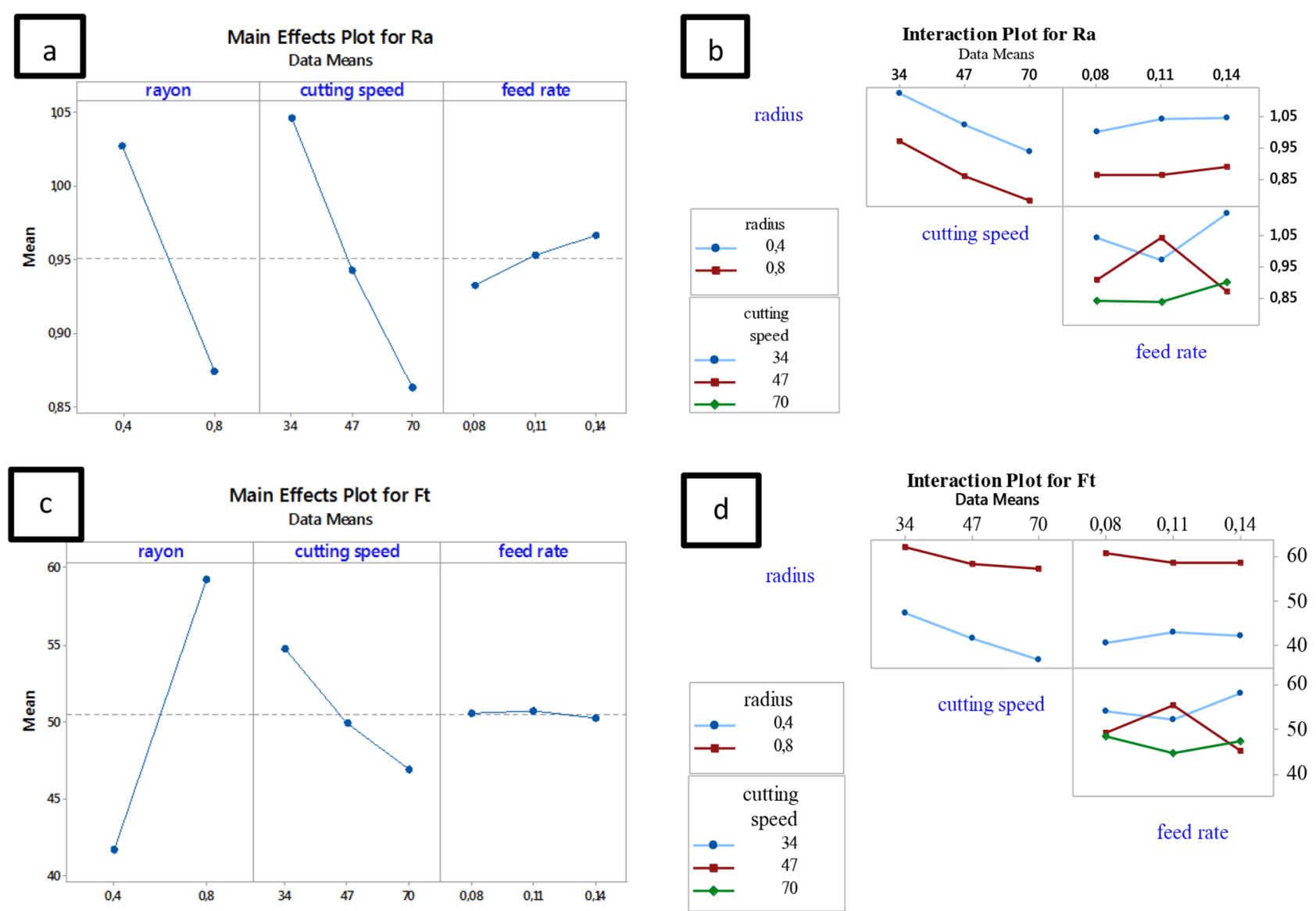

Fig. 10. Main effect and interaction plots for the technological parameters.

Table 11. Confirmation test for the surface roughness and the cutting forces.

\begin{tabular}{|c|c|c|c|c|c|c|}
\hline Test & $r_{\varepsilon}$ & $V_{\mathrm{c}}$ & $f$ & Predicted values & Experimental values & Error \% \\
\hline \multicolumn{7}{|c|}{ Feed force $F_{a}(N)$} \\
\hline 1 & 0.4 & 47 & 0.09 & 11.53 & 11.04 & 4.49 \\
\hline 2 & 0.4 & 70 & 0.12 & 9.95 & 10.68 & 6.87 \\
\hline 3 & 0.8 & 47 & 0.09 & 14.69 & 14.82 & 0.86 \\
\hline 4 & 0.8 & 70 & 0.12 & 12.76 & 12.63 & 1.03 \\
\hline \multicolumn{7}{|c|}{ Tangential force $F_{\mathrm{r}}(\mathrm{N})$} \\
\hline 1 & 0.4 & 47 & 0.09 & 46.53 & 45.81 & 1.57 \\
\hline 2 & 0.4 & 70 & 0.12 & 33.39 & 33.48 & 0.26 \\
\hline 3 & 0.8 & 47 & 0.09 & 81.96 & 82.3 & 0.41 \\
\hline 4 & 0.8 & 70 & 0.12 & 78.43 & 78.4 & 0.05 \\
\hline \multicolumn{7}{|c|}{ Thrust force $F_{t}(\mathbf{N})$} \\
\hline 1 & 0.4 & 47 & 0.09 & 45.16 & 44.32 & 1.89 \\
\hline 2 & 0.4 & 70 & 0.12 & 32.79 & 32.73 & 0.18 \\
\hline 3 & 0.8 & 47 & 0.09 & 61.49 & 62.57 & 1.72 \\
\hline 4 & 0.8 & 70 & 0.12 & 54.80 & 50.35 & 8.83 \\
\hline \multicolumn{7}{|c|}{ Surface roughness $R_{\mathrm{a}}$} \\
\hline 1 & 0.4 & 47 & 0.09 & 1.06 & 0.98 & 0.08 \\
\hline 2 & 0.4 & 70 & 0.12 & 0.89 & 1.00 & 0.10 \\
\hline 3 & 0.8 & 47 & 0.09 & 0.93 & 0.78 & 0.15 \\
\hline 4 & 0.8 & 70 & 0.12 & 0.71 & 0.82 & 0.11 \\
\hline
\end{tabular}




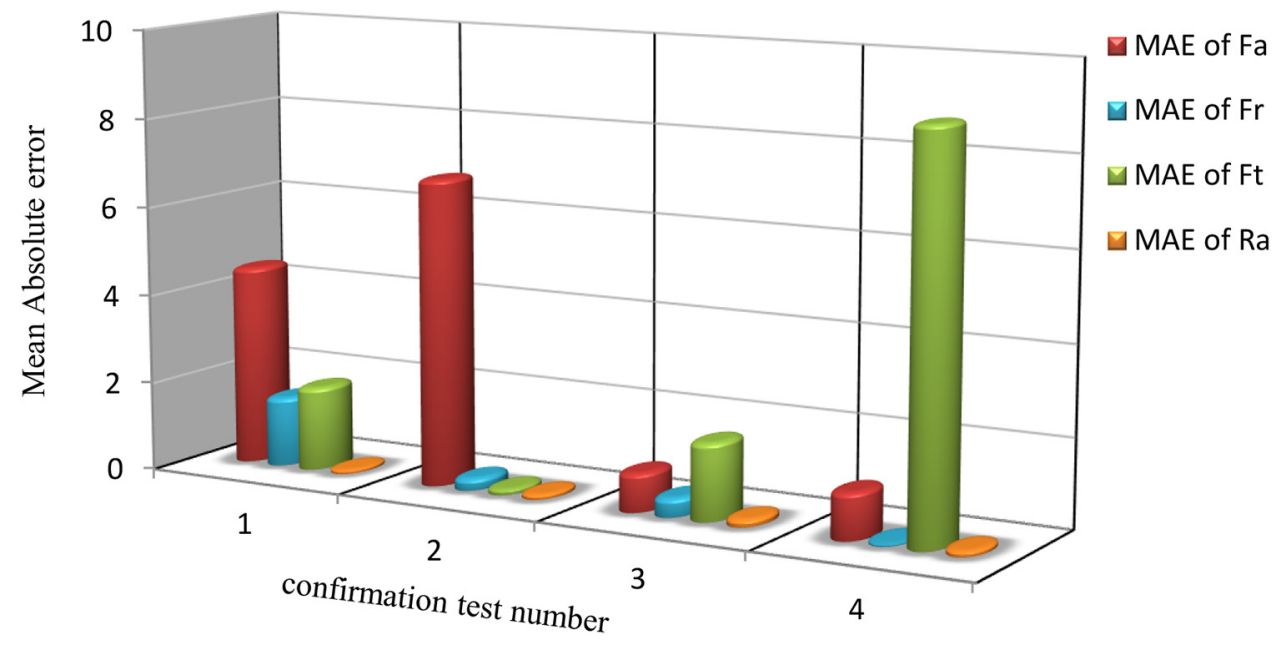

Fig. 11. Mean absolute errors between predicted and experimental results.

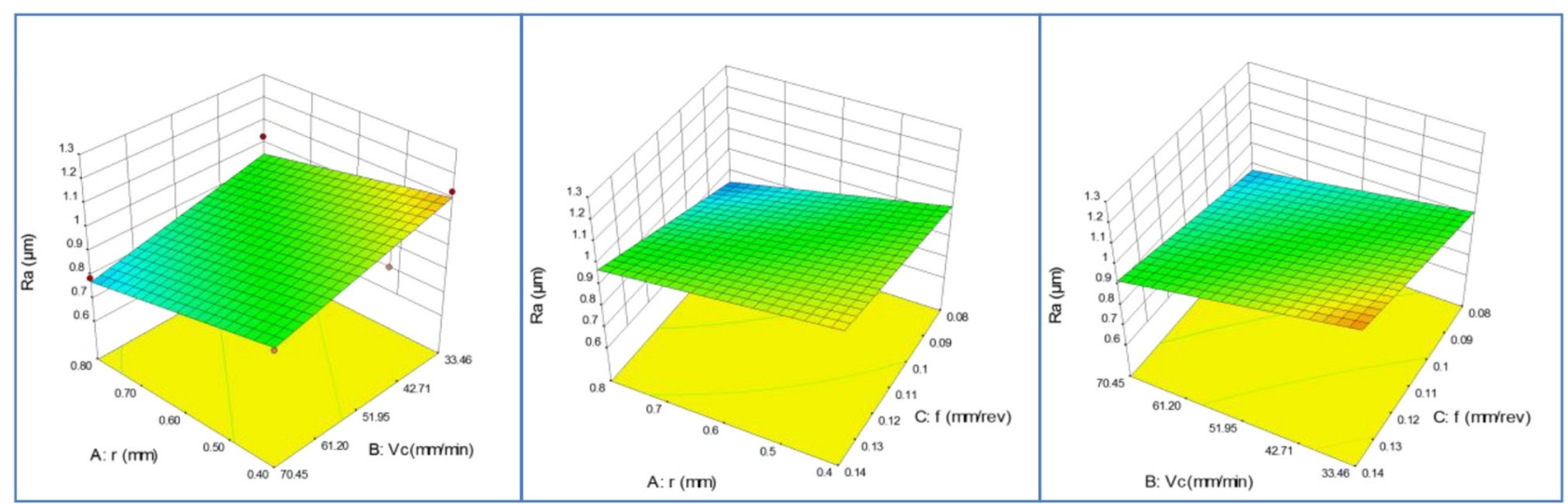

Fig. 12. Estimated response surface for surface roughness.

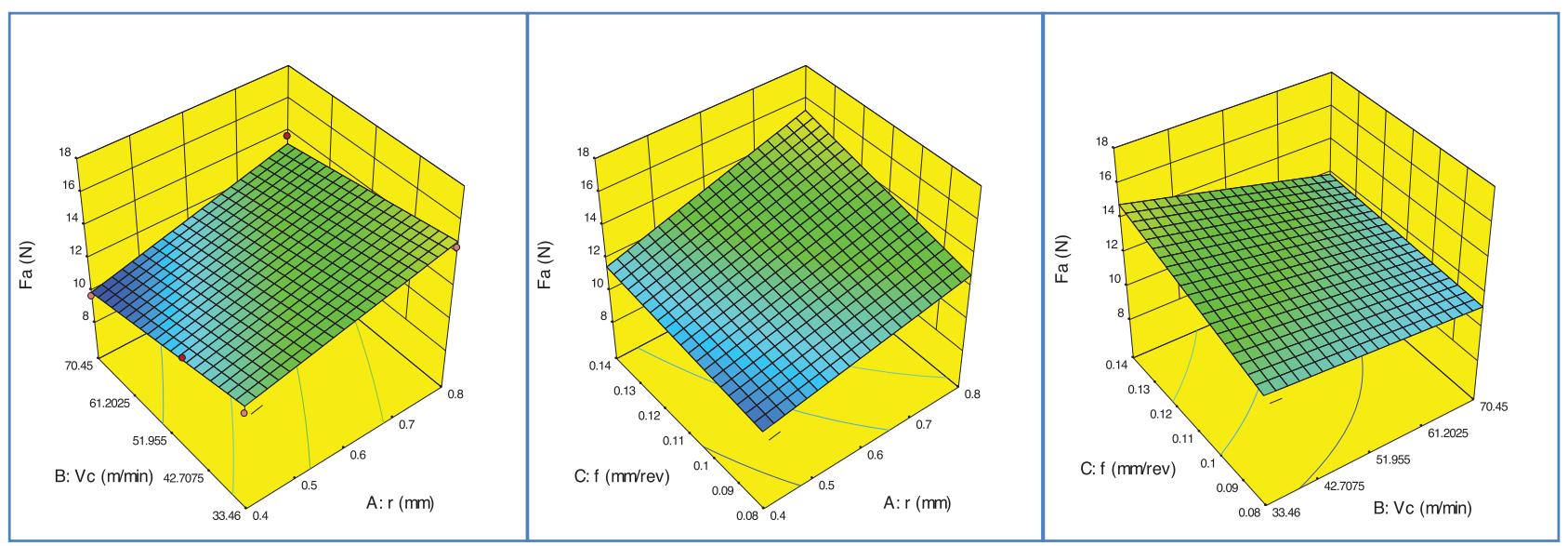

Fig. 13. Estimated response surface for axial force. 


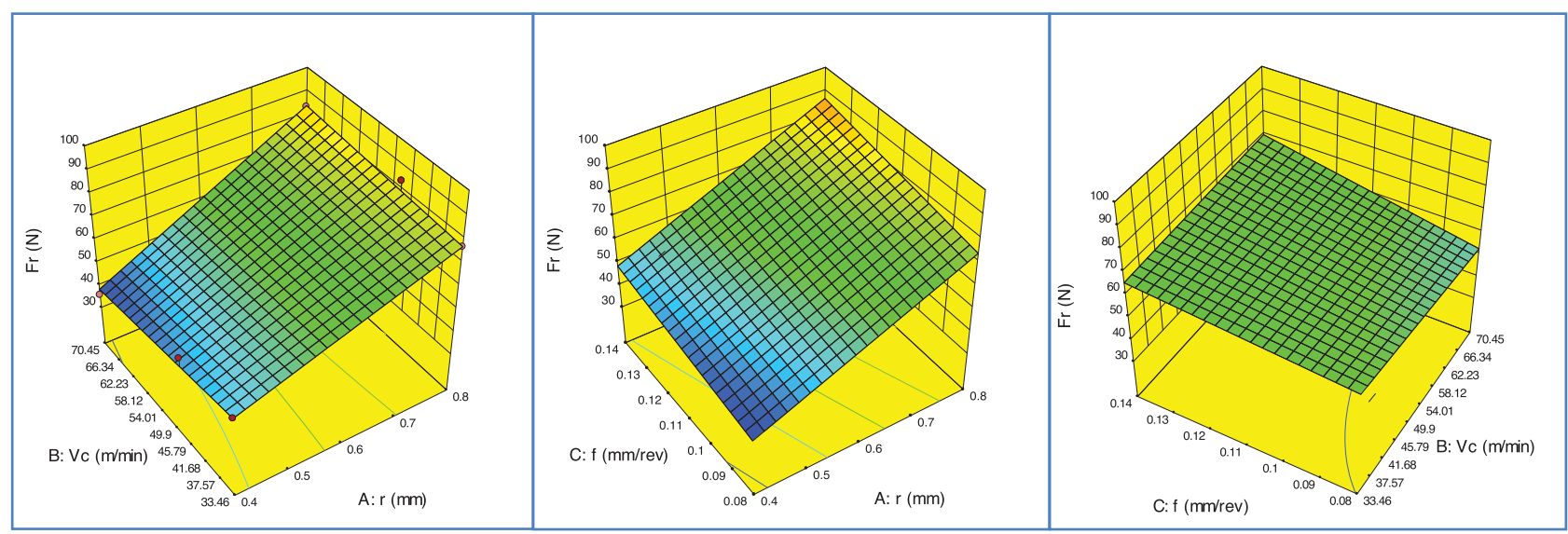

Fig. 14. Estimated response surface for thrust force.

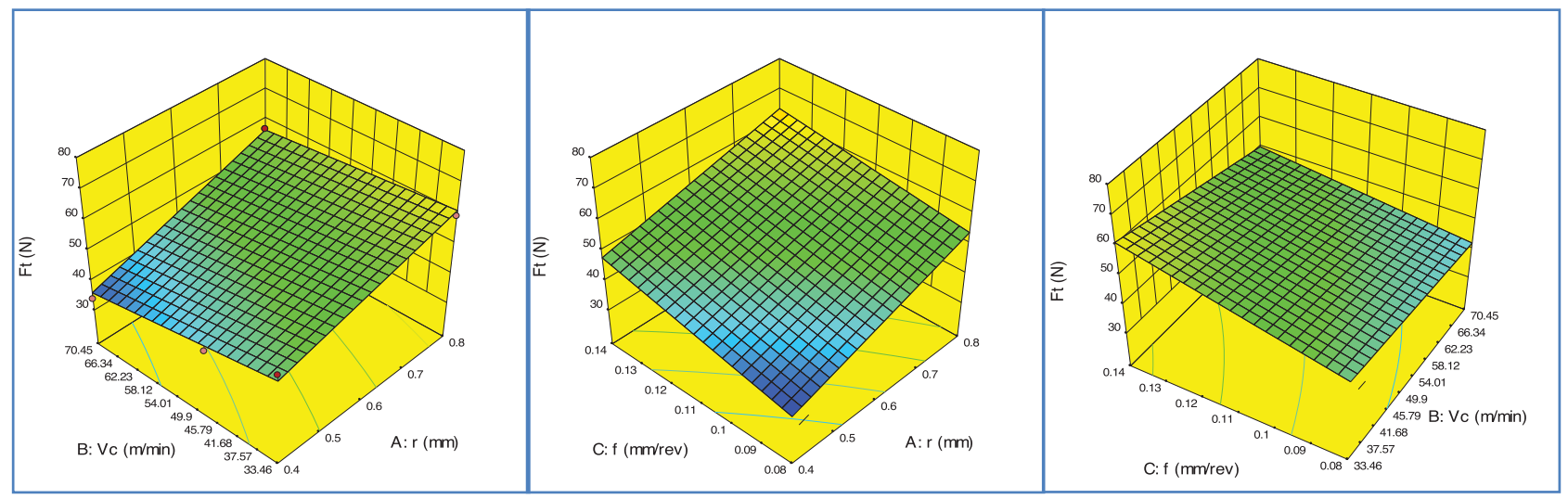

Fig. 15. Estimated response surface for tangential force.

Compared to the effects of the feed rate $(f)$ and the nose radius $\left(r_{\varepsilon}\right)$ shown in Figs. 13b, 14b and $15 \mathrm{~b}$, the cutting speed $\left(V_{\mathrm{c}}\right)$ displays a negligible effect on the cutting forces $\left(F_{\mathrm{a}}, F_{\mathrm{r}}\right.$ and $\left.F_{\mathrm{t}}\right)$. This is clearly demonstrated in Figures $13 \mathrm{a}$ and $\mathrm{c}, 14 \mathrm{a}$ and $\mathrm{c}$ along with $15 \mathrm{a}$ and $\mathrm{c}$.

The contour graphs presented in Figure 16 represent both the insert radius and the feed rate optima for the four response factors represented by $\left(R_{\mathrm{a}}, F_{\mathrm{a}}, F_{\mathrm{r}}\right.$ and $\left.F_{\mathrm{t}}\right)$. Through the contour curves generated by the points displaying the same response, they lead to extracting the needed parameters corresponding to a desirable response point.

\subsection{Multi response optimization - the desirability function}

The analysis of various industrial problems involving conflicting responses needs optimizing them in a simultaneous manner. The desirability function (DF) is extensively used for the optimization of multiple response processes. It is simple and efficient, and enables a multi-objective optimization $[32,33]$. The criterion of the desirability leads to estimating the satisfaction endorsed by the models according to the targeted objectives. To this end, a free value between 0 and 1 is assigned to each response and the multi-objective optimization will determine the different process parameters values that lead to the optimal responses under the specific requirements.

$$
D F=\left(\prod_{i=1}^{n} d_{i}\right)^{\frac{1}{n}} ; F(x)=-D F
$$

$$
\begin{cases}d_{i}=0 & \text { if response } \prec \text { low value } \\ 0 \leq d_{i} \leq 1 & \text { if response varies from low to high } \\ d_{i}=1 & \text { if response }>\text { high value }\end{cases}
$$

$$
\begin{cases}d_{i}=1 & \text { if response } \prec \text { low value } \\ 0 \leq d_{i} \leq 1 & \text { if response varies from low to high } \\ d_{i}=0 & \text { if response }>\text { high value }\end{cases}
$$

where $\left(d_{i}\right)$ represents the desirability of the $i$ th targeted output and $(n)$ is the number of responses. 


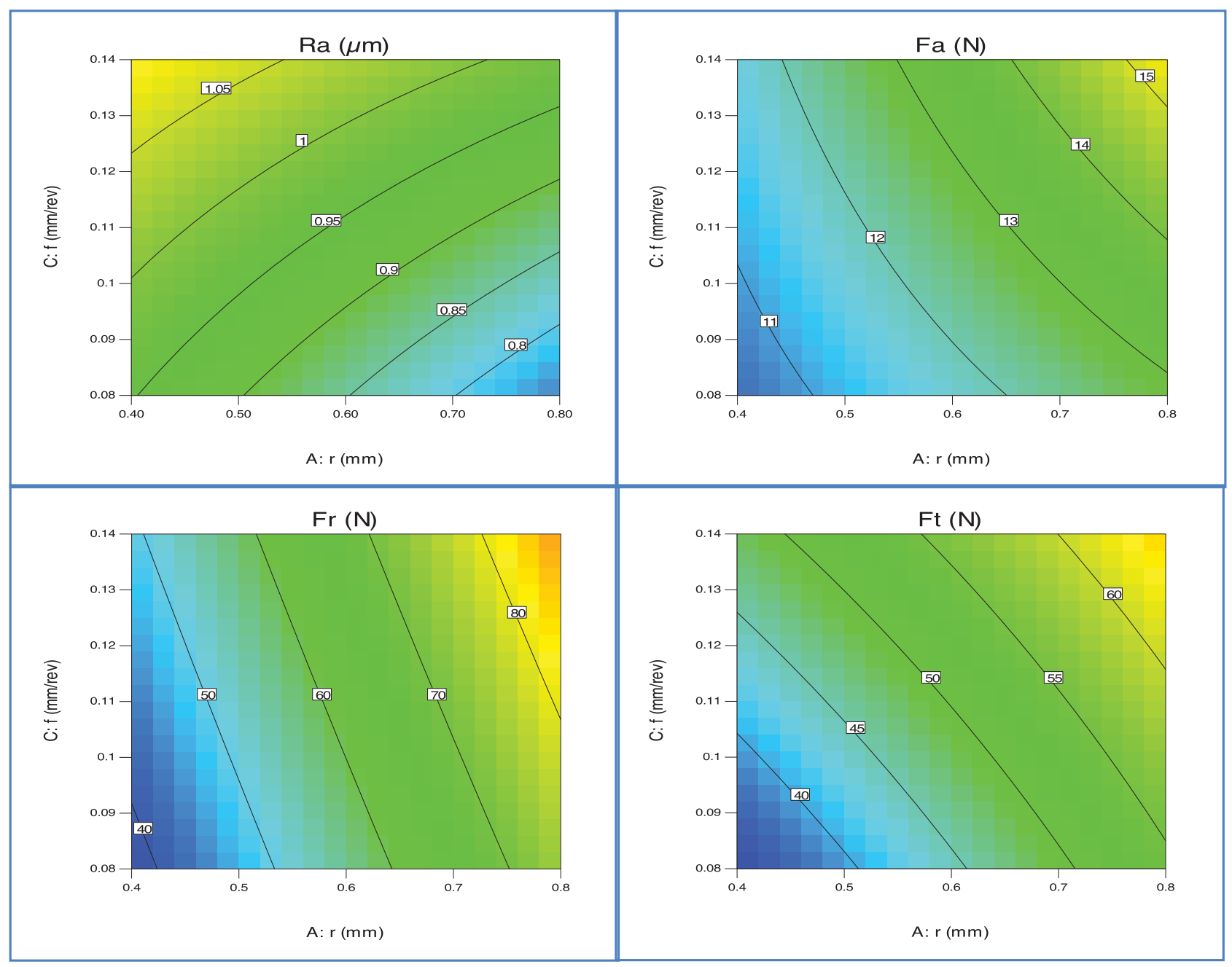

Fig. 16. $R_{\mathrm{a}}, F_{\mathrm{a}}, F_{\mathrm{r}}$ and $F_{\mathrm{t}}$ contour graphs.

The first optimization case is described by equation (11) pertaining to a combined optimization with (DF) as the desirability function and the objective to identify the optimal conditions that lead to simultaneously maximize (DF) and minimize $[F(x)]$. The second case expressed through equation (12) is adopted when searching to maximize the response while the third and last case indicated by equation (13) is exploited when the need for the minimization of the response arises.

The present investigation applied the desirability function in order to find out the optimal values for the response parameters (i.e. $R_{\mathrm{a}}, F_{\mathrm{a}}, F_{\mathrm{r}}$, and $F_{\mathrm{t}}$ ). The primary objective was to identifying the optimal values of the cutting parameters that minimize the surface roughness (quality optimization), reduce the power (energy optimization represented by the cutting force expressed in Eq. (3)), and maximize MRR (represented by the cutting speed expressed in equation (4) and symbolizing productivity optimization). A combination of the three targets will represent the final optimization.

The simulation of this problem is carried out under Design Expert-10-v10.0.1 software, and Table 12 summarizes the various constraints represented by goals, the lower and upper limits, the weights and the importance of each cutting parameter. The four optimization approaches are cited above (i.e. quality, consumption, productivity and a combination of the three). The cutting forces were assigned an importance degree of 5 because they tend to improve the desirability compared to an importance degree of 3 .

Table 13 and Figure 17 displaying the ramp functions graph of the combined optimization exhibit the solutions of the four optimization approaches by disclosing the optimal value for each parameter.

The first case concerns the surface quality optimization represented by the surface roughness $\left(R_{\mathrm{a}}\right)$ which have been assigned the maximum level of importance (5) while the other factors were not considered. The generated optimal results achieved were represented by a minimum surface roughness $\left(R_{\mathrm{a}}=0.68 \mu \mathrm{m}\right)$, high levels for both the nose radius $\left(r_{\varepsilon}=0.8 \mathrm{~mm}\right)$ and the cutting speed $\left(V_{\mathrm{c}}=70 \mathrm{~m} / \mathrm{min}\right)$, and finally a low level for the feed rate $(f=0.08)$. The calculated desirability is found to be $d=0.99$. It is noticed that, as far as the specific surface roughness requirements are concerned, the desirability function is always found close to unity indicating a favorable results achievement by the diverse parameters. 
Table 12. Goals and factors ranges for optimizing quality, productivity and combined case.

\begin{tabular}{llllllll}
\hline & \multicolumn{7}{c}{ Constraints } \\
\cline { 2 - 8 } Name & Approach1 & Approach2 & Approach3 & Approch4 & $\begin{array}{l}\text { Lower } \\
\text { limit }\end{array}$ & $\begin{array}{l}\text { Upper } \\
\text { limit }\end{array}$ & Importance \\
\hline $\mathrm{A}: r_{\varepsilon}$ & In range & In range & In range & In range & 0.4 & 0.8 & 3 \\
$\mathrm{~B}: V_{\mathrm{c}}$ & In range & In range & In range & In range & 34 & 70 & 3 \\
$\mathrm{C}: f$ & In range & In range & In range & In range & 0.08 & 0.14 & 3 \\
$R \mathrm{a}$ & Minimize & None & None & Minimize & 0.68 & 1.21 & 3 \\
$F_{\mathrm{a}}$ & None & Minimize & None & Minimize & 9.72 & 16.96 & 5 \\
$F_{\mathrm{r}}$ & None & Minimize & None & Minimize & 34.77 & 94.6 & 5 \\
$F_{\mathrm{t}}$ & None & Minimize & None & Minimize & 32.52 & 71.05 & 5 \\
$P_{\mathrm{c}}$ & None & Minimize & None & Minimize & 20.61 & 71.69 & 3 \\
$\mathrm{MRR}$ & None & None & Maximize & Maximize & 0.40 & 1.48 & 3 \\
\hline
\end{tabular}

Table 13. Solutions for combined optimization.

\begin{tabular}{lllllllllll}
\hline \multicolumn{10}{c}{ Solutions } \\
\hline Number & $r_{\varepsilon}$ & $V_{\mathrm{c}}$ & $f$ & $R_{\mathrm{a}}$ & $F_{\mathrm{a}}$ & $F_{\mathrm{r}}$ & $F_{\mathrm{t}}$ & $P_{\mathrm{c}}$ & MRR & Desirability \\
\hline 1 & $\underline{0.40}$ & $\underline{70}$ & $\underline{0.09}$ & 0.87 & $\underline{\underline{10}}$ & $\underline{32.59}$ & $\underline{32.52}$ & $\underline{37.642}$ & $\underline{1}$ & $\underline{0.83}$ \\
2 & 0.40 & 70 & 0.09 & 0.87 & $\underline{\underline{10}}$ & 32.65 & 32.56 & 37.638 & 1 & 0.83 \\
3 & 0.40 & 70 & 0.09 & 0.87 & $\underline{\underline{10}}$ & 32.53 & 32.48 & 37.646 & 1 & 0.83 \\
4 & 0.40 & 70 & 0.09 & 0.87 & $\underline{\underline{10}}$ & 32.52 & 32.48 & 37.647 & 1 & 0.83 \\
5 & 0.40 & 70 & 0.09 & 0.87 & $\underline{\underline{10}}$ & 32.88 & 32.70 & 37.629 & 1 & 0.83 \\
\hline
\end{tabular}

The second case investigates the cutting power that was assigned an importance level of (5). The results obtained demonstrate a feed force of $F_{\mathrm{a}}=10.36 \mathrm{~N}$, a thrust force $F_{\mathrm{r}}=34.77 \mathrm{~N}$, a tangential force $F_{\mathrm{t}}=33.06 \mathrm{~N}$ and a cutting power $P_{\mathrm{c}}=33.78 \mathrm{~W}$. This led to a desirability $d=0.92$ and optimal cutting parameters represented by a low level of the nose radius $\left(r_{\varepsilon}=4 \mathrm{~mm}\right)$, a cutting speed of $V_{\mathrm{c}}=$ $59.39 \mathrm{~m} / \mathrm{min}$ and a low level of feed rate $f=0.08 \mathrm{~mm} / \mathrm{rev}$.

The productivity optimization is represented by the maximum productivity $\mathrm{MRR}=1.39 \mathrm{~cm}^{3} / \mathrm{min}$ and a corresponding optimal cutting parameters scaled at the highest levels. The desirability is found to be $d=0.92$, and the cutting parameters represented by the lowest level of the nose radius $r_{\varepsilon}=04 \mathrm{~mm}$, the cutting speed $V_{\mathrm{c}}=62.42 \mathrm{~m} / \mathrm{min}$ along with the lowest level of the feed rate $f=0.08 \mathrm{~mm} / \mathrm{rev}$. The desirability corresponding to minimizing the cutting power and maximizing the productivity is found equal to 0.92 which satisfies greatly the predefined objectives. It may also be acknowledged that the efficiency of the parameters seems greater in the case of maximum quality than in that representing a minimum energy and a maximum productivity $(d=0.99$ in the former case and $d=0.92$ in the latter).

The fourth and last case concerns a combined optimization that integrates the three aforementioned three cases and whose objectives are represented by a minimum surface roughness $\left(R_{\mathrm{a}}\right)$, a minimum cutting power (minimum consumed energy) and a maximum productivity simultaneously. This multi-objective optimization led to $R_{\mathrm{a}}=0.86 \mu \mathrm{m}, F_{\mathrm{a}}=10 \mathrm{~N}, F_{\mathrm{r}}=32.59 \mathrm{~N}, F_{\mathrm{t}}=$ $32.52 \mathrm{~N}, P_{\mathrm{c}}=37.64 \mathrm{~W}$ and $\mathrm{MRR}=1 \mathrm{~cm}^{3} / \mathrm{min}$. The optimal process parameters are further identified as the lowest level of the nose radius $\left(r_{\varepsilon}=0.4 \mathrm{~mm}\right)$, the highest level of the cutting speed $\left(V_{\mathrm{c}}=70 \mathrm{~m} / \mathrm{min}\right)$ and a feed rate of $f=0.9 \mathrm{~mm} / \mathrm{rev}$ with a desirability of $d=0.82$. This combined desirability evaluates how well each process weights on a set of different responses. The results obtained and summarized in Table 13 and Figure 17 exhibit the lowest value of the desirability $(d=0.82)$ indicating the complexity of the present combined optimization mainly due to the great number of conditions it should take into account.

Figure 18 shows the contour graphs of the nose radius $\left(r_{\varepsilon}\right)$, the feed rate $(f)$ and the cutting speed $\left(V_{\mathrm{c}}\right)$ optima for the combined optimization case.

\section{Conclusions}

The present paper provides a study of both the surface roughness and the cutting forces when turning Iconel 718 using carbide inserts. A detailed investigation of the 


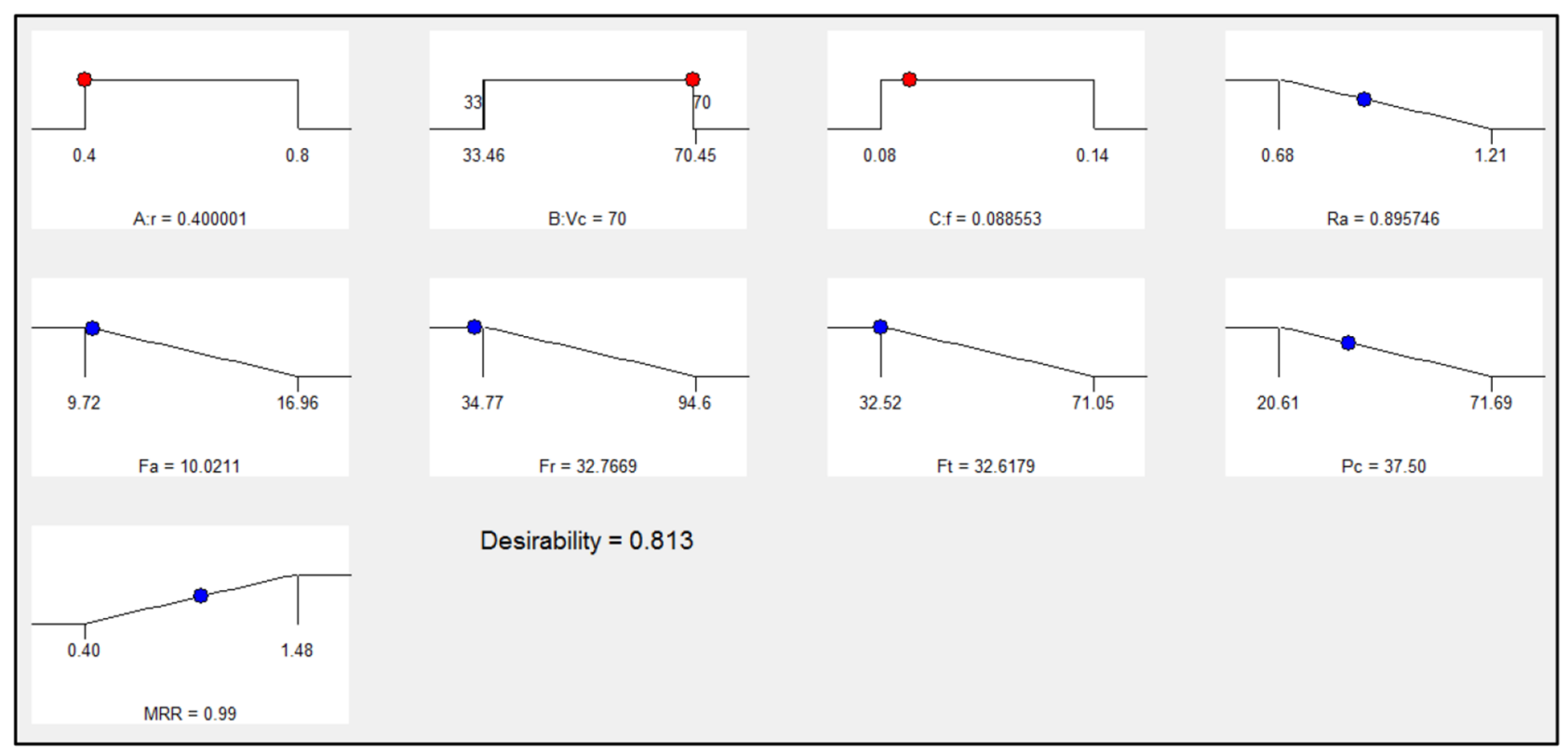

Fig. 17. Ramp function graph of the combined optimization.

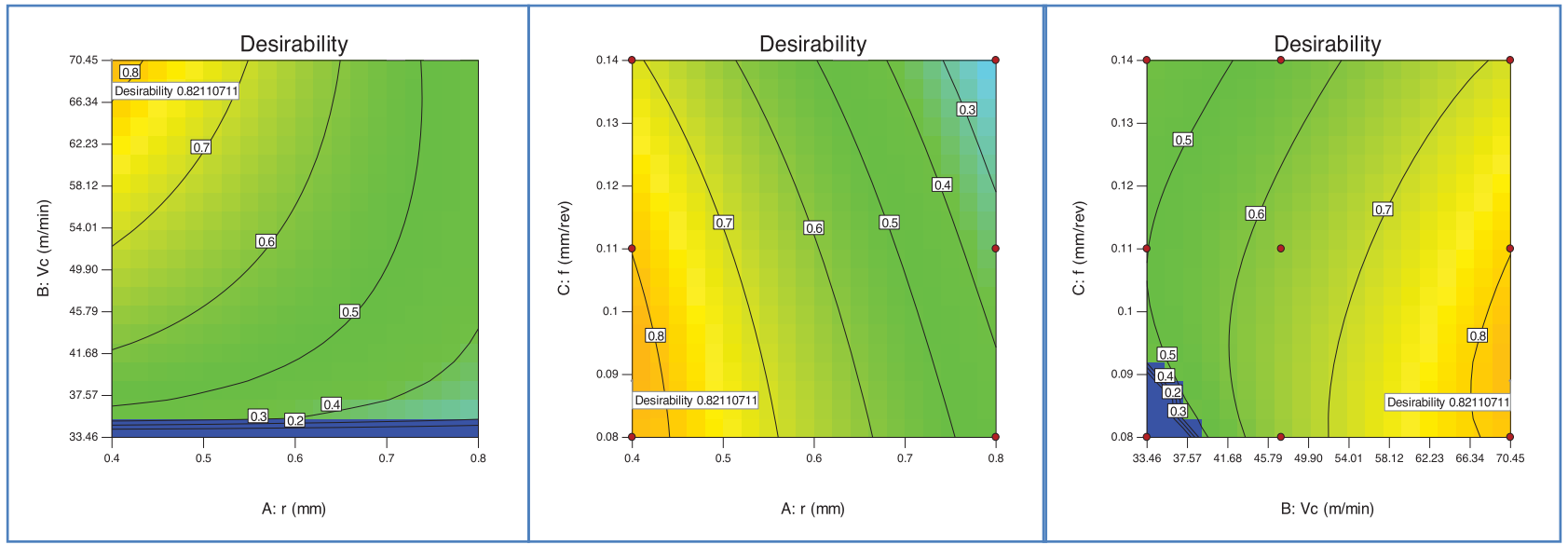

Fig. 18. Desirability contour (multi-objective).

optimization procedure was carried out to identify the optimal cutting parameters that achieve quality, energy and productivity. The results achieved led to the following conclusions:

The analysis proved that the cutting speed and nose radius are the most important parameters influencing the surface roughness $\left(R_{\mathrm{a}}\right)$. Their increase greatly improves the surface roughness. It is also demonstrated that an increase in the depth of cut $\left(a_{\mathrm{p}}\right)$ and the feed rate $(f)$ leads to an increase in $\left(R_{\mathrm{a}}\right)$, and that it is therefore advisable to perform the machining applying their minimum level possible.

In terms of the cutting forces, the impact of the cutting parameters on the three cutting force components seems to be similar. The highest cutting speed is recommended to minimizing the cutting forces. However, these latter were found to increase with the increase of $(f),\left(a_{\mathrm{p}}\right)$ and $\left(r_{\varepsilon}\right)$.
The ANOVA results concerning the cutting forces reveal the nose radius as the most significant parameter affecting the three components of the cutting force, the second significant factor being the cutting speed for the feed force $\left(F_{\mathrm{a}}\right)$ and the feed rate $(f)$ the least influential. Concerning the tangential force $\left(F_{\mathrm{r}}\right)$, the feed rate $(f)$ and the cutting speed $\left(V_{\mathrm{c}}\right)$ come second and third but with relatively limited significance ( 6.15 and $3.03 \%$ respectively) compared with that of the nose radius $r_{\varepsilon}(91.06 \%)$. Regarding the thrust force $\left(F_{\mathrm{t}}\right)$, the nose radius $\left(r_{\varepsilon}\right)$ is identified as the most significant factor followed by the feed rate $(f)$ and the cutting speed $\left(V_{\mathrm{c}}\right)$.

Applied to the surface roughness $\left(R_{\mathrm{a}}\right)$, the ANOVA analysis also demonstrates the nose radius as the most important factor affecting the surface quality with a contribution of $31.81 \%$. It is followed by the feed rate $f$ $(30.07 \%)$ and the cutting speed $V_{\mathrm{c}}(29.23 \%)$. 
The mathematical models developed showed predictive coefficients $\left(R^{2}\right)$ of $95 \%$ for $\left(F_{\mathrm{t}}\right), 98 \%$ for $\left(F_{\mathrm{a}}\right), 97 \%$ for $\left(F_{\mathrm{r}}\right)$ and $95 \%$ for $\left(R_{\mathrm{a}}\right)$ showing a leading to a close description of the characteristics considered.

The confirmation tests display the error pertaining to the experimental vs. the calculated results as reaching a maximum of $9 \%$.

The RSM analysis exhibits the optimal cutting parameters that combine best quality along with utmost energy consumption and best productivity as $r_{\varepsilon}=0.4 \mathrm{~mm}$, $V_{\mathrm{c}}=70 \mathrm{~m} / \mathrm{min}$ and $f=0.09 \mathrm{~mm} / \mathrm{rev}$ with a desirability of 0.83 .

\section{Nomenclature}

ANOVA Analysis of variance

RSM Response Surface Methodology

DF Desirability Function

$r_{\varepsilon} \quad$ Nose radius $(\mathrm{mm})$

$f \quad$ Feed rate $(\mathrm{mm} / \mathrm{rev})$

$a_{\mathrm{p}} \quad$ Depth of cut $(\mathrm{mm})$

$V_{\mathrm{c}} \quad$ Cutting speed $(\mathrm{mm} / \mathrm{min})$

ANN Artificial Neural Network

FDS Fraction Design Space

$R_{\mathrm{a}} \quad$ Arithmetic mean roughness $(\mu \mathrm{m})$

$F_{\mathrm{a}} \quad$ Feed force $(\mathrm{N})$

$F_{\mathrm{r}} \quad$ Thrust force $(\mathrm{N})$

$\mathrm{F}_{\mathrm{t}} \quad$ Tangential force $(\mathrm{N})$

OFAT One-Factor-At-a-Time

$P_{\mathrm{c}} \quad$ Cutting Power (watt)

MRR Material removal rate $\left(\mathrm{cm}^{3} / \mathrm{min}\right)$.

$K_{\mathrm{c}} \quad$ Specific energy or specific pressure (Mpa)

OA Orthogonal array

SS Sums of squares

DF Degrees of freedom

MS Mean square

Contr. \% Contribution ratio (\%)

$R^{2} \quad$ Correlation coefficient

MAE Mean Absolute Error (\%)

The present research has been undertaken in the MAI Laboratory of the National Engineering School of Tunis in association with ADI-Tunisia Company and the LMS research laboratory of the university 8 Mai 1945-Guelma, Algeria. The authors wish to acknowledge these institutions for their support.

\section{References}

[1] F. Alexandre, Probabilistic and microstructural aspects of fatigue crack initiation in the Inconel 718, dissertation, National School of Mines of Paris, 2004

[2] F. Zamzemi, Characterization of Friction Models at ToolChip-to-Chip Interfaces: application to the Machining of Steel and Inconel 718, PhD thesis, Lyon Central School, 2007

[3] M.A. Yallese, L. Boulanouar, K. Chaoui, Usinage de l'acier 100Cr6 trempé par un outil en nitrure de bore cubique, Mech. Ind. 5, 355-368 (2004)
[4] Z. Hessainia, M.A. Yallese, K. Chaoui, T. Mabrouki, J.F. Rigal, On the prediction of surface roughness in the hard turning based on cutting parameters and tool vibrations, Measurement 46 (2013)

[5] M.W. Azizi, S. Belhadi, M.A. Yallese, Surface roughness and cutting forces modeling for optimization of machining condition in finish hard turning of AISI 52100 steel, J. Mech. Sci. Technol. 26, 4105-4114 (2012)

[6] B.A. Khidhir, B. Mohamed, Study of cutting speed on surface roughness and chip formation when machining nickel-based alloy, J. Mech. Sci. Technol. 24, 1053-1059 (2010)

[7] E. Kaya, B. Akyüz, Effects of cutting parameters on machinability characteristics of Ni-based superalloys: a review, Open Eng. 7 (2017)

[8] M. Sarikaya, V. Yılmaz, A. Güllü, Analysis of cutting parameters and cooling/lubrication methods for sustainable machining in turning of Haynes 25 superalloy, J. Clean. Prod. 133, 172-181 (2016)

[9] S.M. Darwish, The impact of tool material and the cutting parameters on surface roughness of supermet 718 nickel superalloy, J. Mater. Process. Technol. 97, 10-18 (2000)

[10] D. Tali, Machinability of Rene 41 Superalloy on Different Turning Parameters, PhD thesis, Eskisehir Osmangazi University, 2016

[11] M. Sarikaya, M. Gullu, Taguchi design and response surface methodology-based analysis of machining parameters in CNC turning under MQL, J. Clean. Prod. 65, 604-616 (2014)

[12] D.M. D'Addonaa, S.J. Raykarb, M.M. Narke, High speed machining of Inconel 718: toolwear and surface roughness analysis, Proc. CIRP 62, 269-274 (2017)

[13] W. Grzesik, P. Nieslony, W. Habrat, J. Sieniawski, Investigation of tool wear in the turning of Inconel 718 superalloy in terms of process performance and productivity enhancement, Tribol. Int. 118, 337-346 (2017)

[14] W. Akthar, J. Sun, P. Sun, W. Chen, Tool wear mechanisms in the machining of Nickel based super-alloys: a review, Front. Mech. Eng. 9, 106-119 (2014)

[15] D. Dudzinski, A. Devillez, A. Moufki, D. Larrouquère, V. Zerrouki, J. Vigneau, A review of developments towards dry and high-speed machining of Inconel 718 alloy, Int. J. Mach. Tools Manuf. 44, 439-456 (2003)

[16] H. Tebassi, M.A. Yallese, R. Khettabi, S. Belhadi, I. Meddour, F. Girardin, Multi-objective optimization of surface roughness, cutting forces, productivity and Power consumption when turning of Inconel 718, Int. J. Ind. Eng. Comput. 7, 111-134 (2016)

[17] H. Tebassi, M.A. Yallese, I. Meddour, F. Girardin, T. Mabrouki, On the modeling of surface roughness and cutting force when turning of Inconel 718 using artificial neural network and response surface methodology: accuracy and benefit, Period. Polytech. Mech. Eng. 61, $1-11$ (2017)

[18] H. Tebassi, M.A. Yallese, S. Belhadi, F. Girardin, Quality-productivity decision making when turning of Inconel 718 aerospace alloy: a response surface methodology approach, Int. J. Ind. Eng. Comput. 8, 347-362 (2017)

[19] S.R. Reddy, M.S. Kumar, V. Vasu, Temperature study in Turning Inconel-718: 3D Simulation and Experimentation, Mater. Today Proc. 4, 9946-9950 (2017) 
[20] A.K. Parida, K. Maity, Effect of nose radius on forces, and process parameters in hot machining of Inconel 718 using finite element analysis, Eng. Sci. Technol. Int. J. 20, 687-693 (2017)

[21] A. Mehta, S. Hemakumar, A. Patil, S.P. Khandke, P. Kuppan, R. Oyyaravelu, A.S.S. Balan, Influence of sustainable cutting environments on cutting forces, surface roughness and tool wear in turning of Inconel 718, Mater. Today Proc. 5, 6746-6754 (2018)

[22] S. Zhang, J.F. Li, Y.W. Wang, Tool life and cutting forces in end milling Inconel 718 under dry and minimum quantity cooling lubrication cutting conditions, J. Clean. Prod. 32, 81-87 (2012)

[23] G. Kartheek, K. Srinivas, Ch. Devaraj, Optimization of Residual Stresses in Hard Turning of Super Alloy Inconel 718, Mater. Today Proc. 5, 4592-4600 (2018)

[24] A.K. Parida, B.C. Routara, R.K. Bhuyan, Surface roughness model and parametric optimization in machining of GFRP composite: Taguchi and Response surface methodology approach, Mater. Today Proc. 2, 3065-3074 (2015)

[25] M. Anthony Xavior, M. Manohar, M.M. Patil, P. Jeyapandiarajanl, Investigation of surface integrity during turning inconel 718, Trans. Canadian Soc. Mech. Eng. 41 (2017)

[26] M. Aruna, V. Dhanalaksmi, Design Optimization of Cutting Parameters when Turning Inconel 718 with Cermet Inserts, World Acad. Sci. Eng. Technol. Int. J. Mech. Mech. Eng. 6 (2012)
[27] A. Devillez, G. Le Coz, S. Dominiak, D. Dudzinski, Dry machining of Inconel 718, workpiece surface integrity, J. Mater. Process. Technol. 211, 1590-1598 (2011)

[28] K. Sunil, D.S. Nirmal, S. Kalsi, Experimental Investigations of Surface Roughness of Inconel 718 under different Machining Conditions, Mater. Today Proc. 4, 1179-1185 (2017)

[29] D.G. Thakur, B. Ramamoorthy, L. Vijayaraghavan, Study on the machinability characteristics of superalloy Inconel 718 during high speed turning, Mater. Des. 30, 1718-1725 (2009)

[30] D. Xuan-Truong, T.M. Duc, Effect of cutting condition on tool wear and surface roughness during machining of Inconel 718, Int. J. Adv. Eng. Technol. 108, 108-112 (2013)

[31] K. Boulahem, S. Ben Salem, J. Bessrour, Prediction model of ultimate tensile strength and investigation on microstructural characterization of friction stir welded AA2024-T3, Int. J. Adv. Manuf. Technol. 95, 1473-1486 (2018)

[32] N.R. COSTA, J. Lourenço, Z.L. Pereira, Desirability function approach: a review and performance evaluation in adverse conditions, Chemometrics and Intelligent Laboratory Systems 107, 234-244 (2011)

[33] A.-A. Selaimia, M.A. Yallese, H. Bensouilah, I. Meddour, R. Khattabi, T. Mabrouki, Modeling and optimization in dry face milling of X2CrNi18-9 austenitic stainless steel using RMS and desirability approach, Measurement 107, 53-67 (2017)

Cite this article as: W. Frifita, S.B. Salem, A. Haddad, M.A. Yallese, Optimization of machining parameters in turning of Inconel 718 Nickel-base super alloy, Mechanics \& Industry 21, 203 (2020) 